\title{
Preindustrial-to-present-day radiative forcing by tropospheric ozone from improved simulations with the GISS chemistry-climate GCM
}

\author{
D. T. Shindell, G. Faluvegi, and N. Bell \\ NASA Goddard Institute for Space Studies, and Center for Climate Systems Research, Columbia University, New York, New \\ York, USA
}

Received: 22 May 2003 - Published in Atmos. Chem. Phys. Discuss.: 28 July 2003

Revised: 2 October 2003 - Accepted: 6 October 2003 - Published: 10 October 2003

\begin{abstract}
Improved estimates of the radiative forcing from tropospheric ozone increases since the preindustrial have been calculated with the tropospheric chemistry model used at the Goddard Institute for Space Studies (GISS) within the GISS general circulation model (GCM). The chemistry in this model has been expanded to include simplified representations of peroxyacetylnitrates and non-methane hydrocarbons in addition to background $\mathrm{NO}_{\mathrm{x}}-\mathrm{HO}_{\mathrm{x}}-\mathrm{O}_{\mathrm{x}}-\mathrm{CO}-\mathrm{CH}_{4}$ chemistry. The GCM has improved resolution and physics in the boundary layer, improved resolution near the tropopause, and now contains a full representation of stratospheric dynamics. Simulations of present-day conditions show that this coupled chemistry-climate model is better able to reproduce observed tropospheric ozone, especially in the tropopause region, which is critical to climate forcing. Comparison with preindustrial simulations gives a global annual average radiative forcing due to tropospheric ozone increases of $0.30 \mathrm{~W} / \mathrm{m}^{2}$ with standard assumptions for preindustrial emissions. Locally, the forcing reaches more than $0.8 \mathrm{~W} / \mathrm{m}^{2}$ in parts of the northern subtropics during spring and summer, and is more than $0.6 \mathrm{~W} / \mathrm{m}^{2}$ through nearly all the Northern subtropics and mid-latitudes during summer. An alternative preindustrial simulation with soil $\mathrm{NO}_{\mathrm{x}}$ emissions reduced by two-thirds and emissions of isoprene, paraffins and alkenes from vegetation increased by $50 \%$ gives a forcing of $0.33 \mathrm{~W} / \mathrm{m}^{2}$. Given the large uncertainties in preindustrial ozone amounts, the true value may lie well outside this range.
\end{abstract}

\section{Introduction}

Changes in atmospheric chemistry since the industrial revolution have had a significant impact on climate and human health, but are difficult to quantify accurately due to their

Correspondence to: D. T. Shindell

(dshindell@giss.nasa.gov) complexity (Intergovernmental Panel on Climate Change (hereafter IPCC), 2001). Increased anthropogenic emissions of ozone precursor gases such as nitrogen oxides $\left(\mathrm{NO}_{\mathrm{x}}\right)$ produce tropospheric ozone, a potent greenhouse gas, and also alter the oxidation capacity of the troposphere. The latter change affects the lifetime of many trace gases, including methane, another powerful greenhouse gas. Tropospheric ozone changes have a spatial pattern that is extremely inhomogeneous, leading to similar inhomogenaity in its radiative forcing. We therefore feel it is useful to explore these chemical changes in a model in which they can be directly coupled to the concurrent climate changes during the past and those projected for the future.

The magnitude of the radiative forcing due to tropospheric ozone increases is relatively uncertain. This uncertainty arises from the paucity of observations during the preindustrial period, and the poor quality of those that do exist. Estimates are therefore based on model simulations, though these are subject to large uncertainties in the emissions of ozone precursors in both modern and especially in preindustrial times, as well as in chemical and physical processes. Though the IPCC presents estimates of the forcing from tropospheric ozone since the preindustrial of $+0.35 \pm 0.15 \mathrm{~W} / \mathrm{m}^{2}$, several recent studies have indicated that the value may actually be significantly larger. These studies are based upon preindustrial emissions of precursors adjusted within their uncertainties to give a better match to the purported 19th century observations of surface ozone (Mickley et al., 2001), or estimates constrained by 20th century observations prior to the late 1970s onset of large amounts of stratospheric ozone depletion by chlorofluorocarbons (Shindell and Faluvegi, 2002). Both studies find that forcings of around $0.7 \mathrm{~W} / \mathrm{m}^{2}$ are reasonable.

Radiative forcing from tropospheric ozone is especially large (per unit ozone change) near the tropopause (Hansen et al., 1997; Hauglustaine and Brasseur, 2001). Estimates of ozone change in this region are therefore especially

(C) European Geosciences Union 2003 
important for evaluating ozone's forcing. Ozone in this region is extremely sensitive to stratosphere-troposphere exchange and to production of $\mathrm{NO}_{\mathrm{x}}$ by lightning (Grewe et al., 2001). Both these factors are only weakly constrained by present-day observations, and are largely unconstrained for the preindustrial era. It is therefore a priority that the chemistry-climate models used to estimate tropospheric ozone's radiative forcing provide accurate simulations in this region.

We have previously developed and evaluated a simplified tropospheric chemistry package within the GISS GCM and used that model to explore the preindustrial to present-day radiative forcing from tropospheric ozone (Shindell et al., 2001). That model has also been applied to studies of the relative importance of individual emission changes and climate responses since the preindustrial (Grenfell et al., 2001) amd for the future (Grenfell et al., 2003), to an investigation of the origin and variability of upper tropospheric nitrogen oxides and ozone (Grewe et al., 2001), and to a study of dynamical-chemical coupling across the tropopause (Grewe et al., 2002). Comparison with observations for that model showed that it was able to simulate tropospheric ozone and related species reasonably well. However, with only 9 vertical layers, that model had very coarse resolution in the vicinity of the tropopause and a poor representation of the stratosphere, so that its primary deficiency was in simulating stratosphere-troposphere exchange and tropopause region ozone accurately. We present here a new version of the GISS coupled chemistry-climate model with greater vertical resolution and a full representation of the stratosphere (though without stratospheric chemistry). Given the resulting large increase in the computational expense of the climate model portion of the simulation, it was relatively inexpensive to add to the chemistry. We have therefore expanded the original simple $\mathrm{HO}_{\mathrm{x}}-\mathrm{NO}_{\mathrm{x}}-\mathrm{O}_{\mathrm{x}}-\mathrm{CO}-\mathrm{CH}_{4}$ chemistry to include isoprene and the peroxyacetylnitrate (PAN), alkene, alkyl nitrate, paraffin and aldehyde families, thus providing a more realistic representation of tropospheric chemistry. This new model has been used to simulate present-day conditions, and has been extensively compared with observations. We have then performed preindustrial simulations, and investigated the resulting radiative forcing.

\section{Model description}

\subsection{Chemistry}

The model includes the basic $\mathrm{HO}_{\mathrm{x}}-\mathrm{NO}_{\mathrm{x}}-\mathrm{O}_{\mathrm{x}}-\mathrm{CO}-\mathrm{CH}_{4}$ chemistry $\left(\mathrm{HO}_{\mathrm{x}}=\mathrm{OH}+\mathrm{HO}_{2} ; \mathrm{NO}_{\mathrm{x}}=\mathrm{NO}+\mathrm{NO}_{2}+\mathrm{NO}_{3}+\mathrm{HONO}\right.$; $\left.\mathrm{O}_{\mathrm{x}}=\mathrm{O}+\mathrm{O}\left({ }^{1} \mathrm{D}\right)+\mathrm{O}_{3}\right)$ described in Shindell et al. (2001), as well as the additional molecules and chemical reactions shown in Tables 1 and 2. We make use of the "chemical family" approach, whereby reactions between family members are assumed to be rapid enough to maintain steady-state (at night, however, $\mathrm{NO}_{\mathrm{x}}$ changes are explicitly calculated). This allows a larger chemical time step and transport of the entire family as a single tracer. We also use "lumped families" for hydrocarbons and PANs, which is necessary for the model to run sufficiently rapidly to be useful for climate studies. Chemical reactions involving these surrogates are based on the similarity between the molecular bond structures within each family using the reduced chemical mechanism of Houweling et al. (1998). This mechanism is based on the Carbon Bond Mechanism-4 (CBM-4) (Gery et al., 1989), modified to better represent the globally important range of conditions. The CBM-4 scheme has been validated extensively against smog chamber experiments and more detailed chemical schemes (Gery et al., 1988; Derwent, 1990; Paulson and Seinfeld, 1992; Tonnesen and Jeffries, 1994). This scheme was modified for use in global models by removing aromatic compounds and adding in reactions important in background conditions, including organic nitrate and organic peroxide reactions, and extending the methane oxidation chemistry. The revised scheme was then readjusted based on the more extensive Regional Atmospheric Chemistry Model (RACM) (Stockwell et al., 1997), and the modified scheme includes several surrogate species designed to compensate for biases relative to the RACM mechanism $\left(\mathrm{XO}_{2}, \mathrm{XO}_{2} \mathrm{~N}\right.$, RXPAR and ROR; see Table 1 for detailed descriptions). The modified scheme was shown to agree well with the detailed RACM reference mechanism over a wide range of chemical conditions including relatively pristine environments (Houweling et al., 1998). Standard gas phase chemical reaction rates have been updated to recent values (Sander et al., 2000).

The chemical family approach of grouping radical species together, along with combining hydrocarbons with similar characteristics into lumped families, permits calculations requiring the transport of only sixteen species in the GCM (Table 1). After combining the short-lived radicals into equilibrated families, we find that nearly all the species have long enough lifetimes that we can use an extremely simple explicit scheme to calculate chemical changes. The exceptions are $\mathrm{HO}_{\mathrm{x}}, \mathrm{CH}_{3} \mathrm{O}_{2}, \mathrm{C}_{2} \mathrm{O}_{3}$, aldehydes and the surrogates $\mathrm{XO}_{2}$, $\mathrm{XO}_{2} \mathrm{~N}$, RXPAR and ROR, whose very short lifetimes keep them in equilibrium at all times. Calculations are performed using a chemical time step of $1 \mathrm{~h}$.

The chemical scheme includes 77 reactions, 25 of which have been added to the previous scheme to account for reactions of PANs and NMHCs (Table 2). The chemistry includes changes in ozone from partitioning within the $\mathrm{NO}_{\mathrm{x}}$ family to avoid spurious ozone sources or sinks associated with the separation of the $\mathrm{O}_{\mathrm{x}}$ and $\mathrm{NO}_{\mathrm{x}}$ families. As with the simpler scheme, heterogeneous hydrolysis of $\mathrm{N}_{2} \mathrm{O}_{5}$ into $\mathrm{HNO}_{3}$ takes place on sulfate aerosols, using the reaction rate coefficients given by Dentener and Crutzen (1993). Sulfate surface areas are taken from an online calculation performed with the 9-layer version of the GISS GCM (Koch et al., 1999), assuming a monodispersed size distribution. Photolysis rates 
Table 1. Gases included in the model

\begin{tabular}{|c|c|c|c|}
\hline Transported & & Not transported & \\
\hline (1) & $\mathrm{O}_{\mathrm{x}}$ & (17) & NO \\
\hline (2) & $\mathrm{NO}_{\mathrm{x}}$ & (18) & $\mathrm{NO}_{2}$ \\
\hline (3) & $\mathrm{HNO}_{3}$ & (19) & $\mathrm{NO}_{3}$ \\
\hline (4) & $\mathrm{N}_{2} \mathrm{O}_{5}$ & (20) & HONO \\
\hline (5) & $\mathrm{HO}_{2} \mathrm{NO}_{2}$ & (21) & $\mathrm{OH}$ \\
\hline (6) & $\mathrm{H}_{2} \mathrm{O}_{2}$ & (22) & $\mathrm{HO}_{2}$ \\
\hline (7) & $\mathrm{CO}$ & (23) & $\mathrm{O}$ \\
\hline (8) & $\mathrm{HCHO}$ & (24) & $\mathrm{O}\left({ }^{1} \mathrm{D}\right)$ \\
\hline (9) & $\mathrm{CH}_{3} \mathrm{OOH}^{b}$ & (25) & $\mathrm{O}_{3}$ \\
\hline (10) & $\mathrm{H}_{2} \mathrm{O}$ & (26) & $\mathrm{CH}_{3} \mathrm{O}_{2}$ \\
\hline (11) & $\mathrm{CH}_{4}{ }^{c}$ & (27) & $\mathrm{C}_{2} \mathrm{O}_{3}$ \\
\hline (12) & $\mathbf{P A N s}^{d}$ & (28) & Aldehydes $^{e}$ \\
\hline (13) & Isoprene & (29) & $\mathbf{X O} \mathbf{O}^{f}$ \\
\hline (14) & Alkyl Nitrates ${ }^{e}$ & (30) & $\mathbf{X} \mathbf{O}_{\mathbf{2}} \mathbf{N}^{g}$ \\
\hline (15) & Alkenes $^{e}$ & (31) & $\mathbf{R X P A R}^{h}$ \\
\hline (16) & Paraffins $^{e}$ & (32) & $\mathbf{R O R}^{i}$ \\
\hline
\end{tabular}

${ }^{a}$ Additional gases in the more comprehensive chemistry scheme are in bold face type.

${ }^{b}$ Methyl hydroperoxide also includes a small contribution from higher organic peroxides.

${ }^{c}$ Transport of methane is optional.

$d$ PANs are peroxyacetylnitrate and higher PANs.

$e$ Alkyl Nitrates, Alkenes, Paraffins, and Aldehydes are lumped families. Alkenes include propene, $>\mathrm{C} 3$ alkenes, and $>\mathrm{C} 2$ alkynes, paraffins include ethane, propane, butane, pentane, >C5 alkanes and ketones, while aldehydes include acetaldehyde and higher aldehydes (not formaldehyde).

${ }^{f} \mathrm{XO}_{2}$ is a surrogate species to represent primarily hydrocarbon oxidation byproducts that subsequently convert $\mathrm{NO}$ to $\mathrm{NO}_{2}$, and also leads to a small amount of organic peroxide formation.

${ }^{g} \mathrm{XO}_{2} \mathrm{~N}$ is a surrogate species to represent hydrocarbon oxidation byproducts that subsequently convert NO to alkyl nitrates, and also leads to a small amount of organic peroxide formation.

${ }^{h}$ RXPAR is a paraffin budget corrector to correct a bias in the oxidation of alkenes related to an overly short chain length for the lumped alkenes.

${ }^{i}$ ROR are radical byproducts of paraffin oxidation.

are calculated every two hours using the Fast-J scheme (Wild et al., 2000), and interact with the GCM's aerosol and cloud fields. Phase transformations of soluble species are calculated based on the GCM's internal cloud scheme. We include transport within convective plumes, scavenging within and below updrafts, rainout within both convective and largescale clouds, washout below precipitating regions, evaporation of falling precipitation, and both detrainment and evaporation from convective plumes (Koch et al., 1999; Shindell et al., 2001). Dry deposition is based on a resistance-inseries calculation and prescribed (i.e. uncoupled) vegetation as described in Shindell et al. (2001). Chemical calculations are performed only in the troposphere in this version of the model (below $150 \mathrm{hPa}$ ), while stratospheric values of ozone, nitrogen oxides, and methane are prescribed according to satellite observations with seasonally varying abundances as in the standard GISS model (Hansen et al., 1996). This implicitly includes stratospheric loss of methane, while other gases with stratospheric sinks are relaxed towards zero based on their chemical lifetime.
The model also includes a full representation of the global methane cycle, including the chemical oxidation chain and detailed emissions and sinks. Though not crucial for the simulations described here, calculation of methane as an active chemical constituent will allow for future investigations of interactions between climate change and methane emissions and oxidation. Note that water vapor is also an active chemical tracer in this model, in contrast to most chemical models which lack a detailed hydrological cycle, and can thus respond to changes in climate via surface temperatures and to altered circulation patterns.

\subsection{Sources and sinks}

Emissions of $\mathrm{NO}_{\mathrm{x}}$ and $\mathrm{CO}$ are largely unchanged from our previous model, based largely on the Global Emissions Inventory Activity (GEIA) data sets (Benkovitz et al., 1996; Olivier et al., 1996) and on Wang et al. (1998a). Total emissions of $\mathrm{CO}$ are $987.7 \mathrm{Tg} / \mathrm{yr}$ (490.1 from biomass burning and 497.6 from industrial activities). Prescribed emissions of $\mathrm{NO}_{\mathrm{x}}$ were $20.9 \mathrm{Tg} / \mathrm{yr} \mathrm{N}$ from fossil fuels, 5.8 from 
Table 2. Additional reactions included in the model ${ }^{a}$

\begin{tabular}{|c|c|c|c|}
\hline & Bimolecular Reactions & $A$ Factor & Activation Temperature \\
\hline (1) & $\mathrm{PAN} \rightarrow \mathrm{C}_{2} \mathrm{O}_{3}+\mathrm{NO}_{2}$ & $2.00 \mathrm{E}+16$ & 13500. \\
\hline \multirow[t]{2}{*}{ (2) } & Isoprene+OH $\rightarrow 0.61 \mathrm{HCHO}+0.58 \mathrm{Alkenes}$ & & \\
\hline & $+0.85 \mathrm{XO}_{2}+0.85 \mathrm{HO}_{2}+0.15 \mathrm{XO}_{2} \mathrm{~N}+0.63$ Paraffin & $2.54 \mathrm{E}-11$ & -410 \\
\hline \multirow[t]{2}{*}{ (3) } & Isoprene $+\mathrm{O}_{3} \rightarrow 0.9 \mathrm{HCHO}+0.55 \mathrm{Alkenes}+0.36 \mathrm{CO}$ & & \\
\hline & $+0.15 \mathrm{C}_{2} \mathrm{O}_{3}+0.63$ Paraffin $+0.30 \mathrm{HO}_{2}+0.18 \mathrm{XO}_{2}+0.28 \mathrm{OH}$ & $1.23 \mathrm{E}-14$ & 2013. \\
\hline \multirow[t]{2}{*}{ (4) } & Isoprene $+\mathrm{NO}_{3} \rightarrow 0.9 \mathrm{HO}_{2}+0.45 \mathrm{Alkenes}+0.9 \mathrm{Alkyl}$ Nitrates + & & \\
\hline & 0.12 Aldehydes $+0.1 \mathrm{NO}_{2}+0.03 \mathrm{HCHO}$ & $7.80 \mathrm{E}-13$ & 0 . \\
\hline (5) & Alkyl Nitrates $+\mathrm{OH} \rightarrow \mathrm{NO}_{2}+\mathrm{XO}_{2}$ & $1.78 \mathrm{E}-12$ & 0 . \\
\hline (6) & Alkenes $+\mathrm{OH} \rightarrow \mathrm{HCHO}+$ Aldehydes $+\mathrm{XO}_{2}+\mathrm{HO}_{2}+\mathrm{RXPAR}$ & $5.20 \mathrm{E}-12$ & 0 . \\
\hline \multirow[t]{2}{*}{ (7) } & Alkenes $+\mathrm{O}_{3} \rightarrow 0.64 \mathrm{HCHO}+0.37 \mathrm{CO}+0.44$ Aldehydes & & \\
\hline & $+0.25 \mathrm{HO}_{2}+0.29 \mathrm{XO}_{2}+0.9 \mathrm{RXPAR}+0.4 \mathrm{OH}$ & $4.33 \mathrm{E}-15$ & 1800. \\
\hline \multirow[t]{2}{*}{ (8) } & Alkenes $+\mathrm{NO}_{3} \rightarrow \mathrm{HCHO}+\mathrm{NO}_{2}+0.91 \mathrm{XO}_{2}$ & & \\
\hline & $+0.09 \mathrm{XO}_{2} \mathrm{~N}+$ Aldehydes$+\mathrm{RXPAR}$ & $7.70 \mathrm{E}-15$ & 0 . \\
\hline \multirow[t]{2}{*}{ (9) } & Paraffin $+\mathrm{OH} \rightarrow 0.11 \mathrm{HO}_{2}+0.87 \mathrm{XO}_{2}+0.76 \mathrm{ROR}$ & & \\
\hline & +0.11 Aldehydes+0.11RXPAR+0.13 $\mathrm{XO}_{2} \mathrm{~N}$ & $8.10 \mathrm{E}-13$ & 0. \\
\hline (10) & Aldehyde $+\mathrm{OH} \rightarrow \mathrm{C}_{2} \mathrm{O}_{3}$ & $7.00 \mathrm{E}-12$ & -250 \\
\hline (11) & Aldehyde $+\mathrm{NO}_{3} \rightarrow \mathrm{C}_{2} \mathrm{O}_{3}+\mathrm{HNO}_{3}$ & $2.50 \mathrm{E}-15$ & 0. \\
\hline (12) & $\mathrm{C}_{2} \mathrm{O}_{3}+\mathrm{NO} \rightarrow \mathrm{HCHO}+\mathrm{NO}_{2}+\mathrm{HO}_{2}+\mathrm{XO}_{2}$ & $3.50 \mathrm{E}-11$ & 180. \\
\hline (13) & $\mathrm{C}_{2} \mathrm{O}_{3}+\mathrm{C}_{2} \mathrm{O}_{3} \rightarrow 2 \mathrm{HCHO}+2 \mathrm{XO}_{2}+2 \mathrm{HO}_{2}$ & $2.00 \mathrm{E}-12$ & 0. \\
\hline \multirow[t]{2}{*}{ (14) } & $\mathrm{C}_{2} \mathrm{O}_{3}+\mathrm{HO}_{2} \rightarrow \mathrm{HCHO}+\mathrm{XO}_{2}+\mathrm{HO}_{2}$ & & \\
\hline & $+0.79 \mathrm{OH}+0.21 \mathrm{CH}_{3} \mathrm{OOH}$ & $6.50 \mathrm{E}-12$ & 0 . \\
\hline \multirow[t]{2}{*}{$(15)$} & $\mathrm{ROR} \rightarrow 1.1$ Aldehyde $+0.94 \mathrm{HO}_{2}+0.96 \mathrm{XO}_{2}$ & & \\
\hline & $+0.04 \mathrm{XO}_{2} \mathrm{~N}+0.02 \mathrm{ROR}+2.1 \mathrm{RXPAR}$ & $1.00 \mathrm{E}+15$ & 8000. \\
\hline (16) & $\mathrm{ROR} \rightarrow \mathrm{HO}_{2}$ & $1.60 \mathrm{E}+03$ & 0. \\
\hline (17) & $\mathrm{XO}_{2}+\mathrm{HO}_{2} \rightarrow \mathrm{CH}_{3} \mathrm{OOH}$ & $3.50 \mathrm{E}-13$ & -1000. \\
\hline (18) & $\mathrm{XO}_{2}+\mathrm{NO} \rightarrow \mathrm{NO}_{2}$ & 4.20E-12 & -180 \\
\hline (19) & $\mathrm{XO}_{2}+\mathrm{XO}_{2} \rightarrow$ & $1.70 \mathrm{E}-14$ & -1300. \\
\hline (20) & $\mathrm{XO}_{2} \mathrm{~N}+\mathrm{NO} \rightarrow$ Alkyl Nitrates & $6.80 \mathrm{E}-13$ & 0. \\
\hline (21) & $\mathrm{XO}_{2} \mathrm{~N}+\mathrm{HO}_{2} \rightarrow \mathrm{CH}_{3} \mathrm{OOH}$ & $(\mathrm{R} 17 \times \mathrm{R} 20) / \mathrm{R} 18$ & \\
\hline (22) & RXPAR+Paraffin $\rightarrow$ & $8.00 \mathrm{E}-11$ & 0 . \\
\hline
\end{tabular}

\begin{tabular}{llllll}
\hline & Termolecular Reactions & $k_{o}$ & $n$ & $k_{\infty}$ & $m$ \\
\hline (23) & $\mathrm{C}_{2} \mathrm{O}_{3}+\mathrm{NO}_{2}+\mathrm{M} \rightarrow \mathrm{PAN}$ & $2.60 \mathrm{E}-28$ & 7.1 & $1.20 \mathrm{E}-11$ & 0.9 \\
\hline & Photolysis Reactions & & & & \\
\hline (24) & PAN $+\mathrm{h} \nu \rightarrow \mathrm{C}_{2} \mathrm{O}_{3}+\mathrm{NO}_{2}$ & & & & \\
(25) & Aldehyde $+\mathrm{h} \nu \rightarrow \mathrm{HCHO}+\mathrm{CO}$ & & & &
\end{tabular}

\footnotetext{
${ }^{a}$ Reaction rates for bimolecular reactions are given by $A \exp ((-E / R)(1 / T)$, where $A$ is the Arrhenius $A$ factor, $E / R$ is the activation temperature of the reaction, and $T$ is the temperature. For termolecular reactions, rates are calculated as a function of the high- and low-pressure reactions rates, given by $k_{\infty}(T / 300)-m$ and $k_{o}(T / 300)-n$, respectively, where $T$ is temperature. In all the above reactions, $\mathrm{M}$ is any body that can serve to carry away excess energy. For reaction 21 , the rate is calculated based on the reaction rates of other reactions, as indicated. All rate coefficients taken from Houweling et al (1998).

$b$ Read $2.00 \mathrm{E}+16$ as $2.00 \times 10^{+16}$.
}

soils, 5.8 from biomass burning, and 0.6 from aircraft (for comparison, internally generated lightning emissions were $6.5 \mathrm{Tg} / \mathrm{yr})$. We have added emissions of isoprene based on Wang et al. (1998a), and alkenes and paraffins also based on GEIA. Global annual average emissions of isoprene were scaled to $200 \mathrm{Tg} / \mathrm{yr}$ from vegetation, as in recent model intercomparisons (IPCC, 2001). Global annual average emissions of alkenes are $32.9 \mathrm{Tg} / \mathrm{yr}$, made up of $16.0 \mathrm{Tg} / \mathrm{yr}$ from vegetation, $11.6 \mathrm{Tg} / \mathrm{yr}$ from industry, and $5.3 \mathrm{Tg} / \mathrm{yr}$ from biomass burning. The largest single contributor is propene, which makes up nearly half the emissions for this family, with other alkenes and alkynes also contributing. Global annual average emissions of paraffins are $87.0 \mathrm{Tg} / \mathrm{yr}$, made up of $14.0 \mathrm{Tg} / \mathrm{yr}$ from vegetation, $68.8 \mathrm{Tg} / \mathrm{yr}$ from industry, and $4.2 \mathrm{Tg} / \mathrm{yr}$ from biomass burning. For the industrial component, butane, pentane and higher alkanes are the largest sources, with smaller contributions from ethane and propane. The biomass burning component is dominated by ethane emissions. For 
both the alkene and paraffin families, the spatial and temporal distribution of isoprene emissions was used for vegetation, and that of carbon monoxide for biomass burning, for lack of further information, with the overall source value scaled to the emissions given above. Distributions of industrial emissions of alkenes and paraffins are from GEIA.

Methane emissions were based upon the data sets of Fung et al. (1991) (available at http://www.giss.nasa.gov/data/ ch4fung). These fields were scaled to values within recent estimates of individual source strengths and their uncertainties (World Meteorological Organization (hereafter WMO), 1999), but maintaining the spatial distributions of the original data sets. The only exception was wetland emissions, which were shifted in latitude towards the tropics (x 1/3 poleward of $30^{\circ}$ in both hemispheres, $x 10 / 4$ from $30^{\circ} \mathrm{S}-30^{\circ} \mathrm{N}$ ) to match more recent estimates of their meridional distribution (WMO, 1995), and increased in magnitude to be more in line with recent estimates (Hein et al., 1997; Walter et al., 2001). Total emissions are $464.0 \mathrm{Tg} / \mathrm{yr}$, made up of emissions from the following individual sources (in $\mathrm{Tg} / \mathrm{yr}$ ): animals (enteric fermentation in ruminants plus animal waste) 83.9, coal mining 20.1, pipeline leakage of natural gas 24.8 , venting of natural gas at wells 17.0 , landfills (including municipal solid waste) 27.5 , termites 20.0 , coal burning 16.0 , ocean (including 3.0 from hydrates) 13.0, fresh water 5.0, miscellaneous ground sources (volcanoes and hydrothermal vents) 7.0 , biomass burning 30.0 , rice cultivation 30.0 , wetlands and tundra 209.7. Loss of methane via absorption into soils is also included, with a value of $-39.9 \mathrm{Tg} / \mathrm{yr}$ (Fung et al., 1991; WMO, 1994). Biomass burning, rice cultivation and wetlands/tundra include seasonal emission cycles.

As in the older model, the GISS convection scheme is used to derive both the total lightning and the cloud-to-ground lightning frequencies interactively in each grid box and at each time step (Price et al., 1997). Then the generation of $\mathrm{NO}_{\mathrm{x}}$ from lightning is used to derive the $\mathrm{NO}_{\mathrm{x}}$ produced, including a C-shaped vertical distribution (Pickering et al., 1998).

\subsection{Climate model}

The climate model used here is a version of the GISS model II' (two-prime) enhanced over that used previously with updated planetary boundary layer and convection schemes. Briefly, the GCM's boundary layer employs a finite modified Ekman layer with parameterizations for drag and mixing coefficients based on similarity theory, convection includes entraining and nonentraining plumes, mass fluxes proportional to convective instability, explicit downdrafts, and a cloud liquid water scheme, based on microphysical sources and sinks of cloud water, which carries both water and ice (Del Genio et al., 1996). Simulations of the response to the eruption of Mt. Pinatubo with a similar version of the GCM (Hansen et al., 1996) show that the tropospheric water vapor response is comparable to observations. This provides

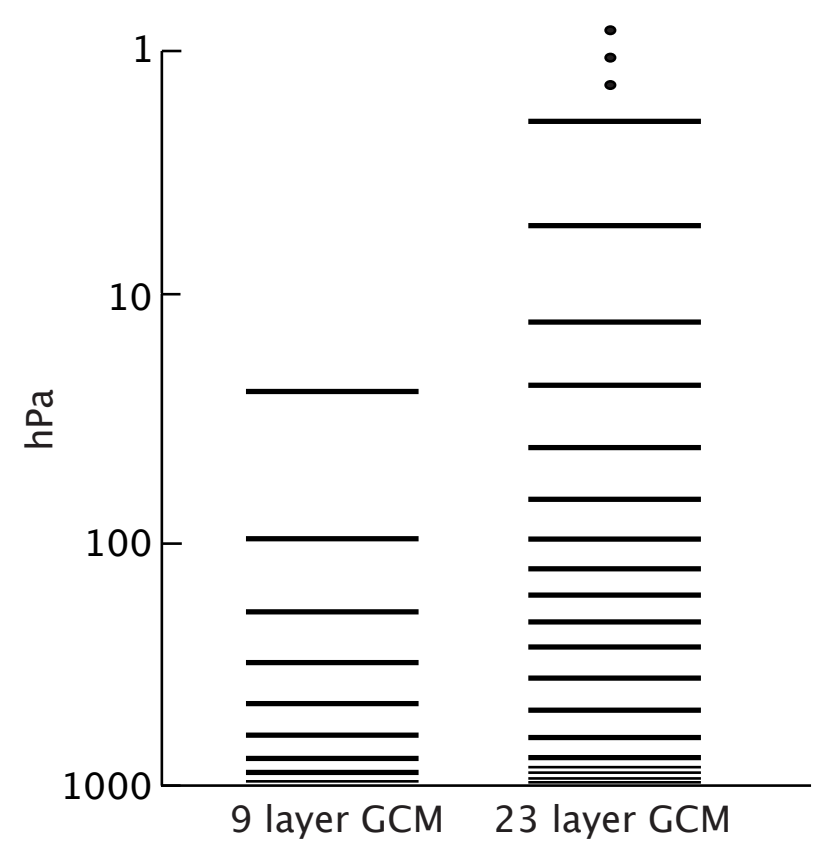

Fig. 1. Vertical layering in the older 9-layer model (layer centers at $959,894,786,634,468,321,201,103$, and $26.5 \mathrm{hPa}$ ) and in the new 23-layer model (layer centers at 972, 945, 907, 852, 765, 640, 498, 370, 280, 219, 171, 134, 102, 71.2, 43.9, 24.7, 13.9, 7.32, 3.05, $0.960,0.303,0.088$, and $0.017 \mathrm{hPa}$ ). The four highest layers of the 23-layer model are not shown.

some evidence that the response of the hydrological cycle to climate forcing in the GCM is realistic. The land surface parameterization calculates transpiration, infiltration, soil water flow and runoff, all of which impact both water vapor and latent heat release to the atmosphere. Chemical tracers, along with heat and moisture, are advected using a quadratic upstream scheme (Prather, 1986). Momentum advection uses a fourth-order scheme. The model's interhemispheric exchange time is 1.45 years (defined here as the difference in annual average mean methane mass between the hemispheres dived by the net annual average cross-equatorial mass flux), within $15-25 \%$ of values deduced from observations. Within the GISS chemistry modeling group we have focused on improving those aspects of the circulation that we believed would be most crucial for correctly simulating stratospheretroposphere exchange. The gravity-wave drag scheme in this model version has been tested extensively and is now able to reproduce observed wind and temperature climatologies much better than in previous versions. This has led to notably improved transport of ozone down from the stratosphere, for example, which was heavily biased towards high latitudes and had an incorrect seasonal cycle in other model versions.

All simulations with the new chemistry have been performed using a version with $4 \times 5^{\circ}$ horizontal resolution and 23 vertical layers. Compared with the older model, the vertical resolution has been significantly improved in both the 
boundary layer and near the tropopause, both regions crucial to ozone simulations, in addition to adding layers in the stratosphere (Fig. 1). The bottom 11 layers of this model are terrain-following levels, while the top 12 are constant pressure surfaces. The model time-step is one hour for both the chemistry and physics. Ozone calculated by the chemical model is coupled to the GCM's radiation calculation, so that chemical changes are able to affect meteorology. Monthly mean sea-surface temperatures and sea ice cover are prescribed to 1990-1999 average values (Rayner et al., 2003) in these simulations for computational savings. Therefore the climate is not fully responsive to the chemistry. The importance of such coupling will be investigated in future simulations. All results presented here are averages over the last five years of seven year simulations. The model reaches equilibrium within the first year (methane values are prescribed according to observations, and other gases have lifetimes of about a month or less), and the interannual variability is relatively small compared to features of interest, so that five years gives us adequate statistics for mean values. The model has been run for present-day (1990) and for preindustrial $(\sim 1850)$ conditions. Additionally, a run with the older chemistry package lacking PANs and hydrocarbons higher than methane has been performed with the 23-layer GCM. This helps isolate the influence of the increased vertical resolution from the effect of the more sophisticated chemistry.

The more comprehensive chemistry scheme adds only about $24 \%$ to the running time of the GCM, plus an additional $\sim 15 \%$ for the transport of the chemical tracers, for a total increase of only $\sim 40 \%$. It is therefore computationally rapid enough that the GCM can be run with online chemistry for long-term climate simulations or for multiple runs to examine the sensitivity of the results to various changes. Though the fractional time used for chemistry is less for the more complex chemistry in the 23-layer model than for the simplified chemistry in the 9-layer model ( $\sim 40 \%$ versus $\sim 55 \%$ ), this is only because the physics takes much longer in the 23-layer version, where the calculations are both more sophisticated and done on more vertical levels. The absolute time taken by the more complex chemistry is roughly a factor of 3 greater than for the simplified chemistry, both due to the increase in the number of reactions and tracers and to the increase of nearly a factor of two in the number of vertical levels within the troposphere.

\section{Evaluation of present-day simulation}

\subsection{Ozone}

We have compared modeled annual cycles of ozone with the ozonesonde climatology of Logan (1999). Comparisons at stations representative of a wide range of latitudes are shown in Fig. 2. Results from the earlier 9-layer model with simplified chemistry are also shown (for these comparisons, we have interpolated between model levels to the exact pressure levels of the sonde data, leading to slight differences as compared with the results shown for the older model in Shindell et al., 2001). The new model clearly does a better job at matching the observations than the older model at the levels nearest the tropopause ( 125 and $200 \mathrm{hPa}$ ). This holds for both the tropics, where the ozone is primarily of tropospheric origin, and for middle and high latitudes, where for at least part of the year the air is primarily of stratospheric origin. At $200 \mathrm{hPa}$, a positive bias in the tropics in the 9-layer model has been eliminated. Comparison of the results from the 23-layer simulations using simplified chemistry against those with the more advanced scheme show that the improvement in this region results primarily from an improved representation of tropical upwelling rather than from chemistry. The model has difficulty reproducing the spring maximum in ozone at $200 \mathrm{hPa}$ at Northern middle and high latitudes, though it does this fairly well in the Southern Hemisphere. This maximum is stratospheric air, and thus may indicate biases in the stratospheric ozone climatology. In fact, a minor flaw in the prescription of the climatology was discovered after completing the analysis of these simulations, which will be corrected in future work, and appears to correct the springtime values. It should also be noted that the vertical gradient of ozone is extremely large at these altitudes, so that small differences in height can lead to ozone changes of hundreds of ppbv (this is true at $125 \mathrm{hPa}$ as well). It may be that a near-perfect match with sondes can therefore only be obtained with extremely high vertical resolution in this area. For those locations and seasons dominated by tropospheric air (i.e. with ozone values less than about 150 ppbv, such as Hohenpeissenberg during September and October and Lauder during January to April), the model does an excellent job of reproducing observed values. Results are fairly similar in the middle troposphere between the old and new models, though the positive bias at high latitudes is somewhat worse in the new version. Fortunately, these locations are less important for radiative forcing. Near the surface most locations show small improvements, while the comparison with Hohenpeissenberg measurements is greatly improved. We attribute this largely to improvements in the boundary layer scheme of the GCM, including the higher vertical resolution there which allow more realistic dry deposition. Similar improvements in near-surface ozone values were seen at Pretoria and Sapporo (not shown). Note that the sonde values at $950 \mathrm{hPa}$ are interpolated from the reported observations at 1000 and $900 \mathrm{hPa}$ where available, and are based upon the $900 \mathrm{hPa}$ values for the higher elevation sites where the $1000 \mathrm{hPa}$ level is not available.

We compare the ability of the two model versions to reproduce the observations over all the sites recommended for testing models by Logan(1999) in Table 3. As noted, the quality of the new model's ozone simulation has improved markedly in the vicinity of the tropopause and near the surface. Biases in the vicinity of the tropopause are now very small. Though 


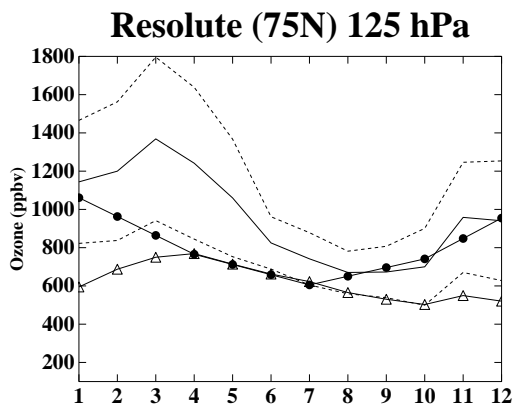

$200 \mathrm{hPa}$

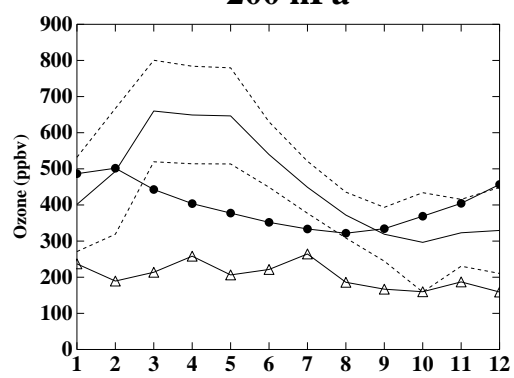

$300 \mathrm{hPa}$

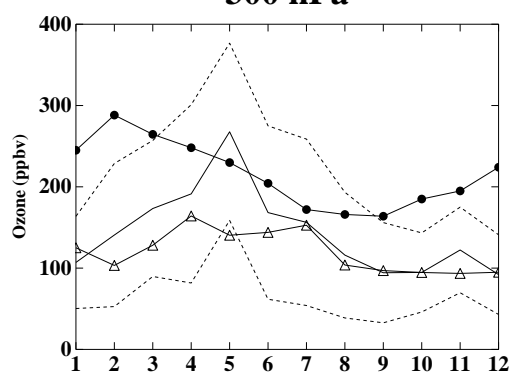

$500 \mathrm{hPa}$

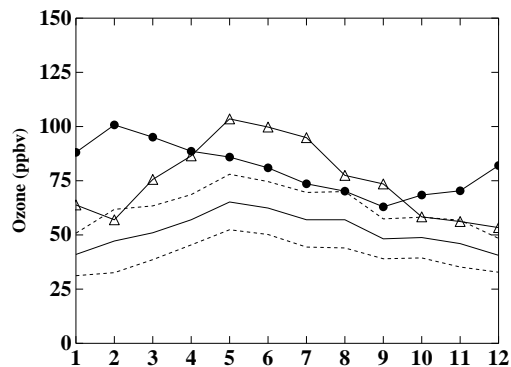

$950 \mathrm{hPa}$

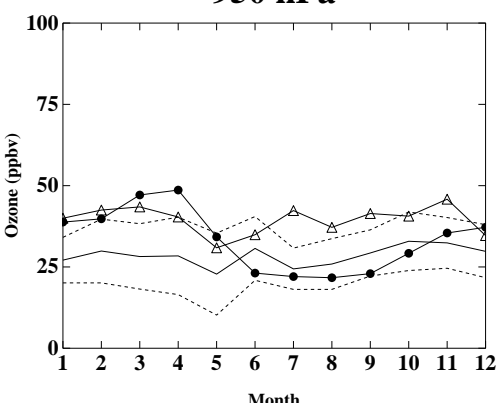

Hohenpeissenberg (48N) $125 \mathrm{hPa}$

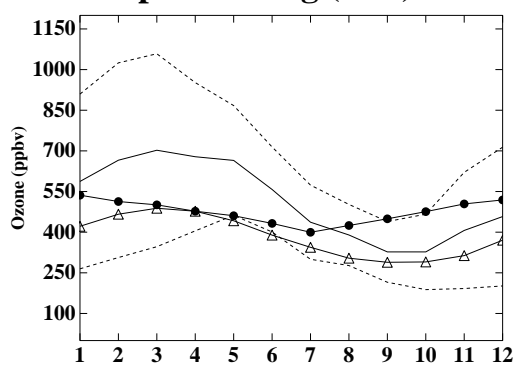

$200 \mathrm{hPa}$

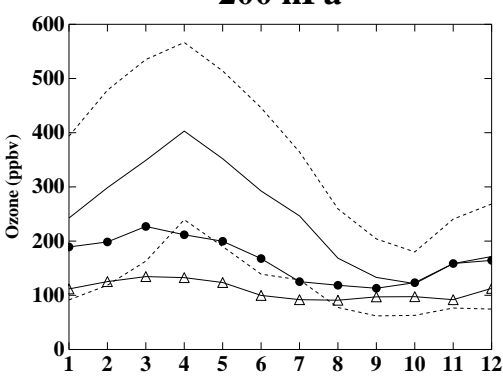

$300 \mathrm{hPa}$

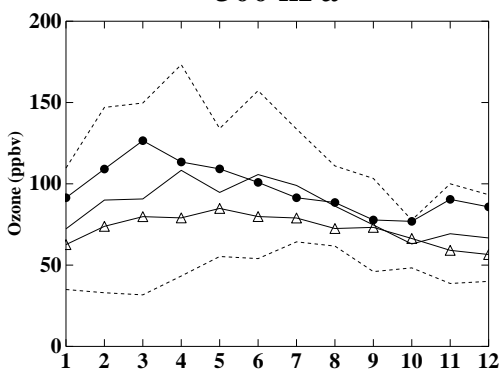

$500 \mathrm{hPa}$

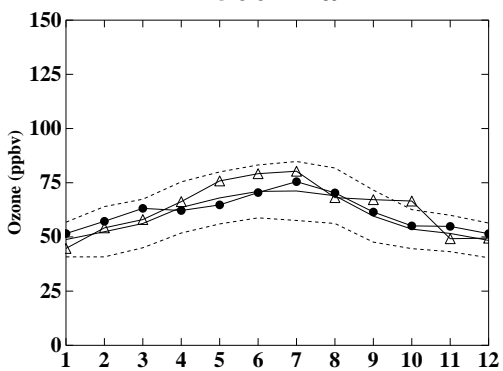

$950 \mathrm{hPa}$

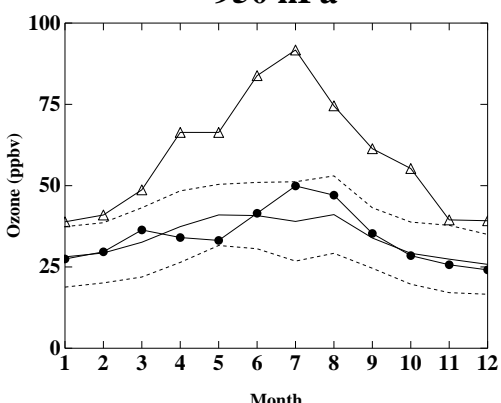

Hilo (20N) $125 \mathrm{hPa}$

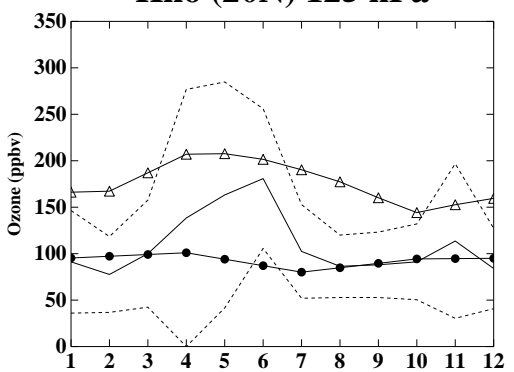

$200 \mathrm{hPa}$

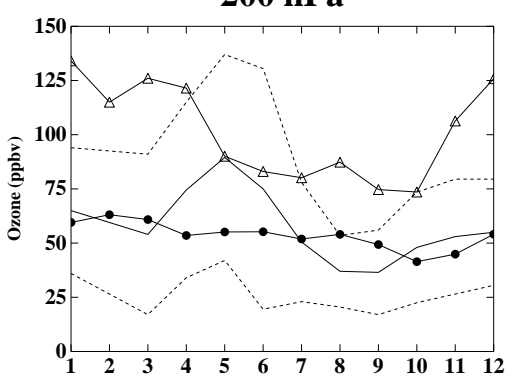

$300 \mathrm{hPa}$

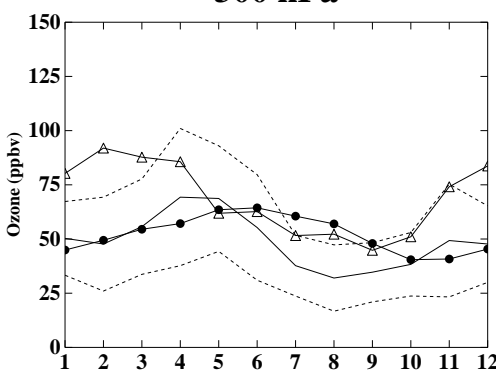

$500 \mathrm{hPa}$

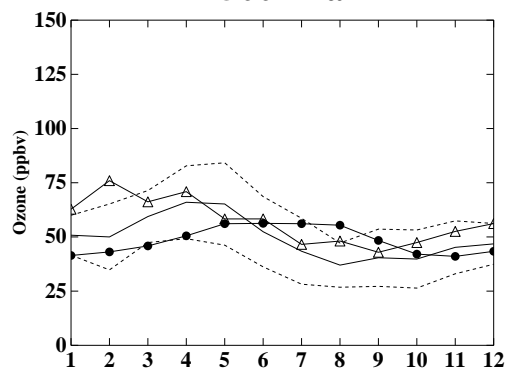

$950 \mathrm{hPa}$

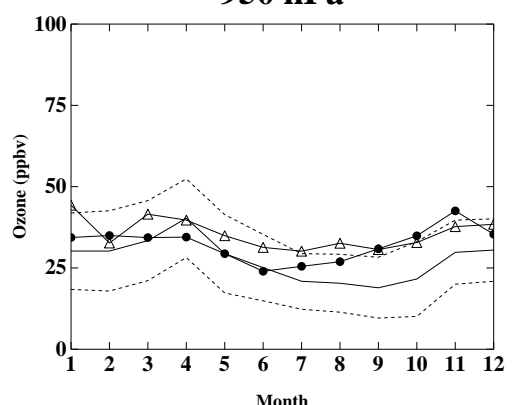

Fig. 2. Comparison of observed and simulated annual cycles of ozone at the indicated pressure levels and locations. Solid and dotted lines indicate ozonesonde measured mean values and standard deviations, respectively. Solid circles show mean values from the new model while open triangles show values from the older model. All values are mixing ratios in ppbv, and model values have been interpolated to the given sonde pressure levels. 


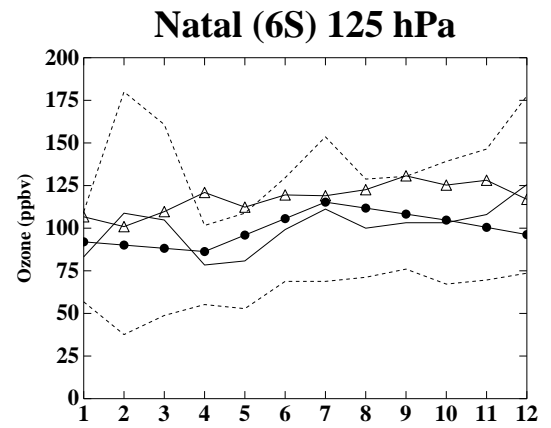

$200 \mathrm{hPa}$

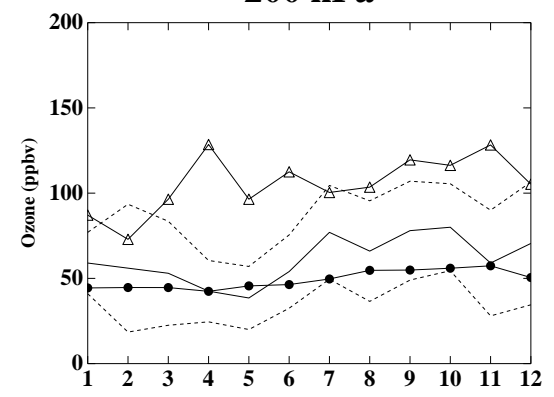

$300 \mathrm{hPa}$

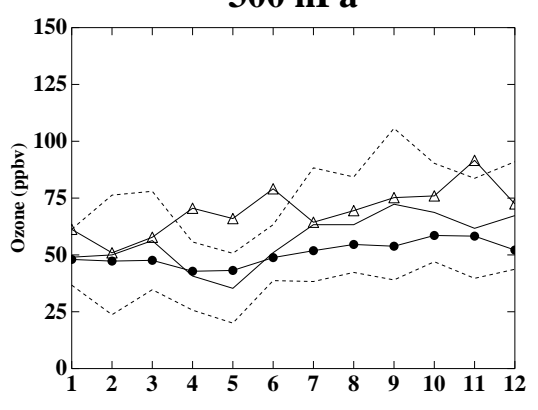

$500 \mathrm{hPa}$
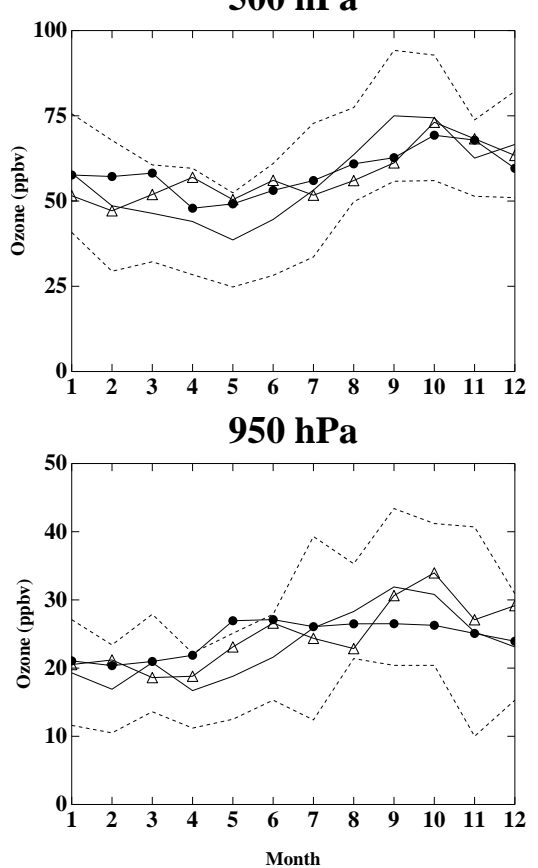

Fig. 2. Continued.

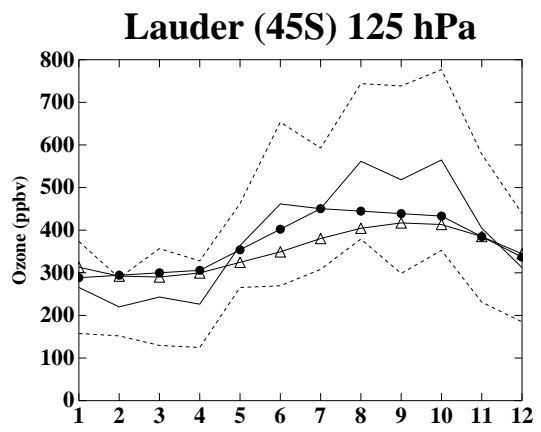

200 hPa

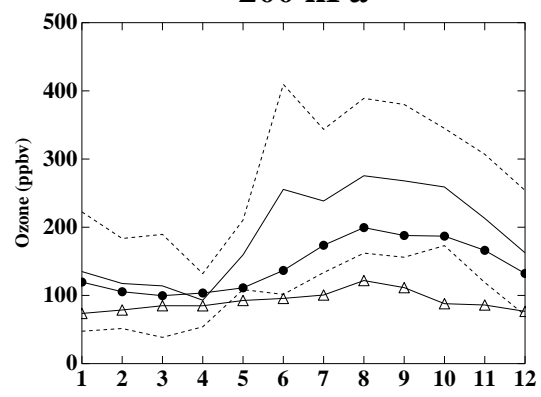

$300 \mathrm{hPa}$

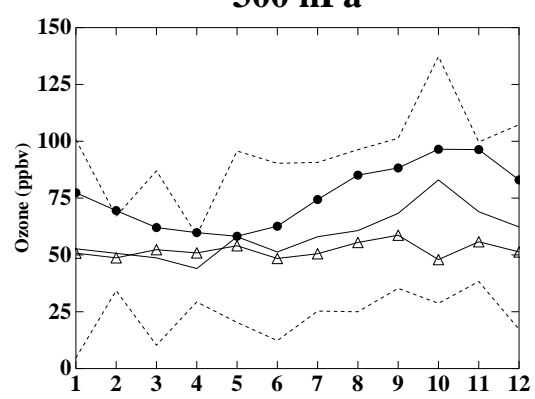

$500 \mathrm{hPa}$

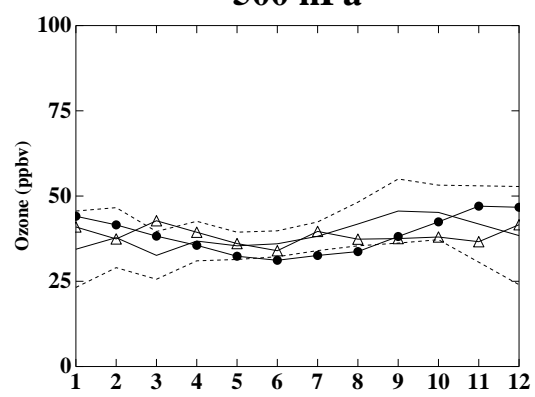

$950 \mathrm{hPa}$

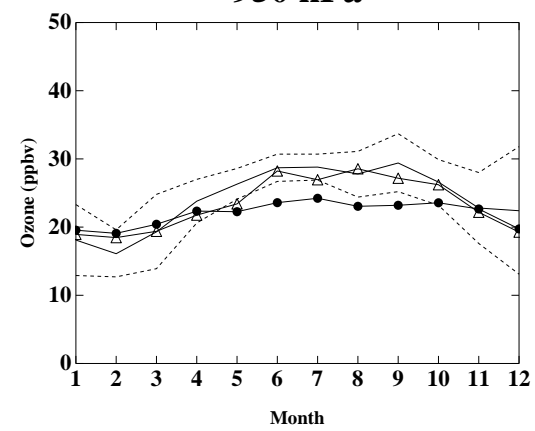

Syowa (69S) 125 hPa

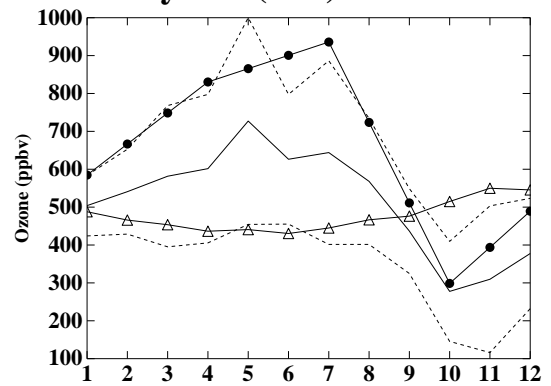

$200 \mathrm{hPa}$

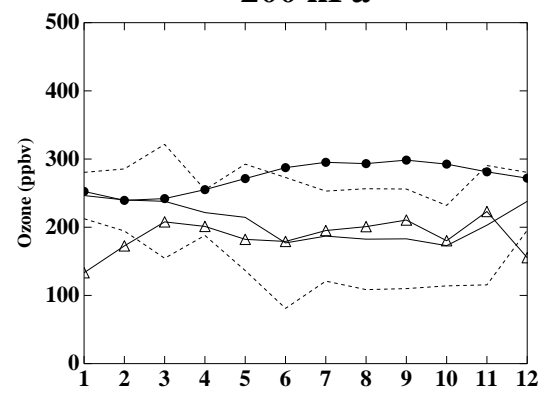

$300 \mathrm{hPa}$

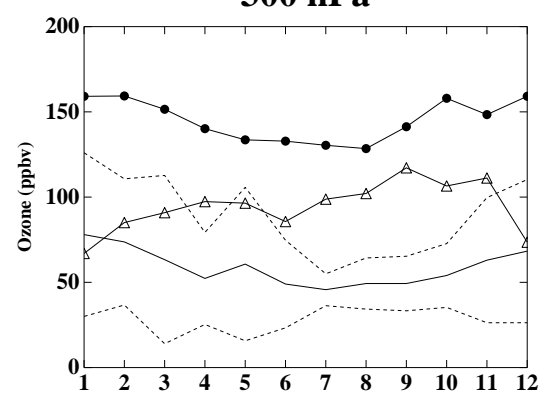

500 hPa

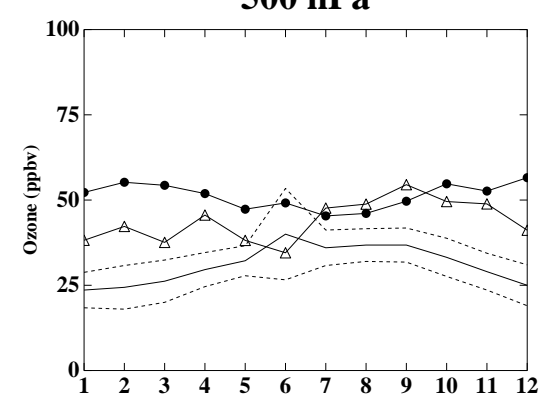

$950 \mathrm{hPa}$

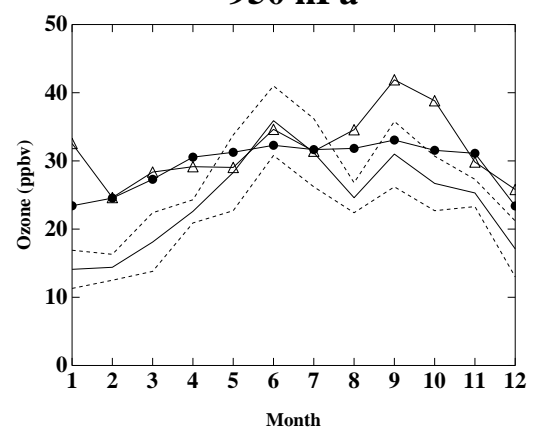


Table 3. Ozone differences (ppbv) between models and sondes

\begin{tabular}{|c|c|c|c|c|c|c|c|}
\hline $\begin{array}{l}\text { Pressure } \\
\text { level (hPa) }\end{array}$ & $\begin{array}{l}\text { Average } \\
\text { difference } \\
\text { 9-layer } \\
\text { model, all } \\
\text { sites }\end{array}$ & $\begin{array}{l}\text { Average } \\
\text { difference, } \\
\text { 23-layer } \\
\text { model, all } \\
\text { sites }\end{array}$ & $\begin{array}{l}\text { Average } \\
\text { bias, } \\
\text { 9-layer } \\
\text { model, all } \\
\text { sites }\end{array}$ & $\begin{array}{l}\text { Average } \\
\text { bias, } \\
\text { 23-layer } \\
\text { model, all } \\
\text { sites }\end{array}$ & $\begin{array}{l}\text { Average } \\
\text { difference, } \\
\text { 23-layer } \\
\text { model, } \\
\text { w/o } \\
\text { high- } \\
\text { latitude } \\
\text { sites }\end{array}$ & $\begin{array}{l}\text { Average } \\
\text { bias, } \\
\text { 23-layer } \\
\text { model, } \\
\text { w/o } \\
\text { high- } \\
\text { latitude } \\
\text { sites }\end{array}$ & $\begin{array}{l}\text { Observed } \\
\text { standard } \\
\text { deviation, } \\
\text { all sites }\end{array}$ \\
\hline 125 & 108.6 & 83.7 & $\begin{array}{l}-18.7 \\
(5 \%)\end{array}$ & $10.6(3 \%)$ & 72.4 & $13.6(3 \%)$ & 137 \\
\hline 200 & 79.5 & 44.9 & $\begin{array}{l}-46.8 \\
(23 \%)\end{array}$ & $\begin{array}{l}-24.9 \\
(12 \%)\end{array}$ & 37.9 & $\begin{array}{l}-29.0 \\
(14 \%)\end{array}$ & 74.2 \\
\hline 300 & 15.1 & 28.9 & $5.8(8 \%)$ & $\begin{array}{l}20.8 \\
(28 \%)\end{array}$ & 21.3 & $\begin{array}{l}12.5 \\
(17 \%)\end{array}$ & 32.2 \\
\hline 500 & 9.3 & 10.6 & $7.5(16 \%)$ & $5.3(11 \%)$ & 8.7 & $2.5(5 \%)$ & 11.4 \\
\hline 950 & 9.3 & 6.9 & $7.7(31 \%)$ & $2.0(8 \%)$ & 6.8 & $1.5(6 \%)$ & 9.9 \\
\hline
\end{tabular}

Comparisons are between the 23-layer model and the 16 recommended sites of Logan (1999), having excluded the two sites with four months or less data. Average differences are from the month-by-month absolute value differences between the model and the sondes. Average biases are with no absolute value included. Values in parentheses are percent bias with respect to observed values at these levels. The sites are: Resolute, Edmonton, Hohenpeissenberg, Sapporo, Boulder, Wallops Island, Tateno, Kagoshima, Naha, Hilo, Natal, Samoa, Pretoria, Aspendale, Lauder, and Syowa.

the $125 \mathrm{hPa}$ level is often in the stratosphere, and thus merely reflects the climatology, improvements in the tropics, where this level is in the troposphere, have reduced the bias there from $5 \%$ to $3 \%$ comparing the new model to the older version. At $200 \mathrm{hPa}$, the bias has been greatly reduced, from $23 \%$ to $12 \%$. The average difference, for which positive and negative errors do not cancel out, has also dropped in this model, by $44 \%$ at $200 \mathrm{hPa}$. A similar level of improvement has been obtained at low levels, where biases have dropped to $11 \%$ and $8 \%$ at 500 and $950 \mathrm{hPa}$, respectively, from $16 \%$ and $31 \%$ in the older model. Similar improvements are apparent when examining the average absolute differences. In the middle troposphere, however, the average absolute difference between the model and the observations has increased. Evaluation of the average bias reveals that this results largely from a consistent positive bias in this region, much of which comes from the two high-latitude sites (Table 3). This likely results from deficiencies in the GCM's downward transport of stratospheric air at high latitudes, which also seems to affect the $500 \mathrm{hPa}$ level at high latitudes. The positive bias at $300 \mathrm{hPa}$ may also be related to the lightning $\mathrm{NO}_{\mathrm{x}}$ production, which may be on the high side though it is well within current uncertainty (see below, and note that reduced lightning $\mathrm{NO}_{\mathrm{x}}$ would worsen the negative bias at $200 \mathrm{hPa}$ ). Except for the $300 \mathrm{hPa}$ level, however, the systematic bias averaged over all 16 sites is roughly $10 \%$ or less. The average absolute difference between the model and the measurements is well within the observed standard deviation at all levels.

The model does a fairly good job of reproducing both the magnitude and seasonality of tropospheric ozone based on the comparisons shown in Fig. 2, and is certainly improved over the previous simulations. While comparison between the 23-layer runs with simplified and advanced chemistry shows few obvious areas of improvement in the ozone fields, we nevertheless believe that incorporation of the advanced chemistry allows better simulation of tropospheric ozone in remote regions (where little validation data is available) and of ozone changes as a function of time, as well as doing a better job with other trace gases.

Surface ozone is shown in Fig. 3. Observations are well reproduced over most regions in this model. Beginning with remote regions, the model's surface level ozone over the remote North Atlantic during January is slightly greater than observations, 35-45 ppbv as compared with measurements showing values of 30-40 ppbv (Parrish et al., 1998). The observational data however include only 4 years of measurements from Sable Island $\left(44^{\circ} \mathrm{N}, 60^{\circ} \mathrm{W}\right)$ and a single year from the Azores $\left(39^{\circ} \mathrm{N}, 28^{\circ} \mathrm{W}\right)$, so should be treated with some caution. At Izana $\left(28^{\circ} \mathrm{N}, 16^{\circ} \mathrm{W}\right)$, slightly farther south over the Atlantic, the model underpredicts January ozone by $8.5 \mathrm{ppbv}$, and July ozone by $2.0 \mathrm{ppbv}$, while the annual average model bias there is -7.0 ppbv. While the values are sometimes higher and sometimes lower than observations, overall the model seems to do a reasonable job over the remote Atlantic, though the model's maximum may be too far north in January. The addition of PANs has increased the amount of ozone in remote regions of the Northern Hemisphere, causing an increase relative to the older model. In remote regions of the Southern Hemisphere, the model does an excellent job of reproducing the observed values. The 

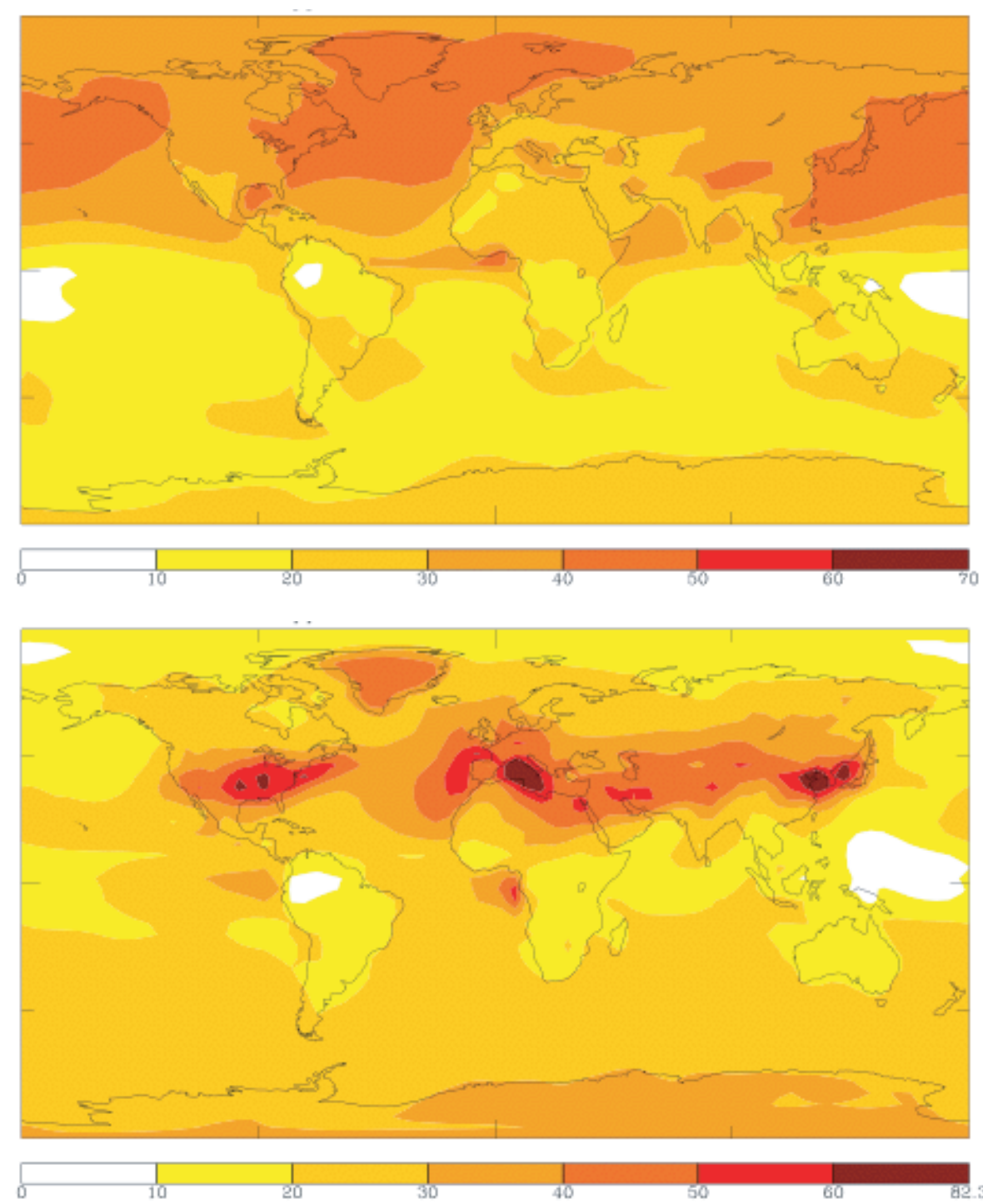

Fig. 3. Modeled ozone values (ppbv) in the lowest model layer for the present day. (top) January near-surface values, and (bottom) July values.

model finds July values of $25-35 \mathrm{ppbv}$ at Syowa station, a location where most models underpredict ozone (Shindell et al., 2001). Over the Southern Hemisphere continents, surface ozone has decreased significantly compared with the previous model version. For example, surface ozone over South America has dropped from 30-45 ppbv in the previous version to only $5-20 \mathrm{ppbv}$ in the current model. The very low values seen in the new model during summer, 5-15 ppbv over the Amazon basin and 10-20 over the Brazilian savannah, are in agreement with measurements taken during the ABLE-2A summer campaign which showed near-surface ozone values of about 8-16 ppbv over the Amazon and slightly larger values over the savannah (Kirchoff, 1988; Emmons et al., 2000). We attribute this change to the inclusion of non-methane hydrocarbons, especially isoprene, which in regions with rela- tively low abundances of $\mathrm{NO}_{\mathrm{x}}$ lead to ozone destruction. Values over the Southern Hemisphere oceans are quite similar in the two models, supporting a terrestrial influence.

A detailed comparison between land-based, primarily rural surface ozone observations and the simulations has been made using the climatology of Logan (1999), based on data from 40 locations (Sanhueza et al., 1985; Cros et al., 1988; Kirchhoff and Rasmussen, 1990; Oltmans and Levy, 1994; Sunwoo and Carmichael, 1994). Results from a sample of sites are presented in Fig. 4. Clearly the model's very low values over South America are in fact in good agreement with observations at Venezuela and Cuiaba. Surface ozone in the tropics is generally well-simulated, with both the large seasonal cycles at Bermuda and Japan Island and the smaller seasonality at Samoa, Barbados and Natal 

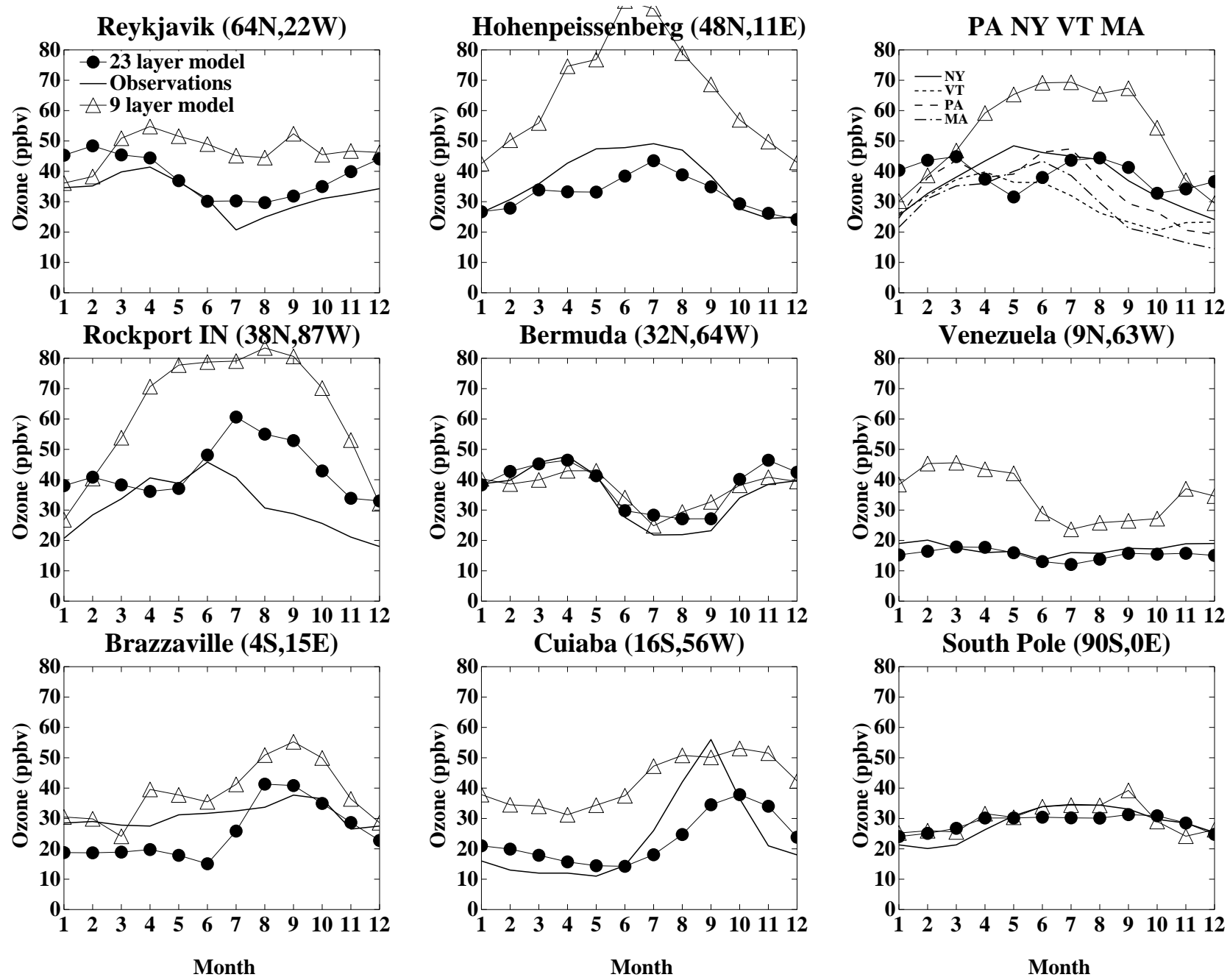

Fig. 4. Comparison of observed and simulated surface ozone. Solid lines indicate observations, while solid circles and open triangles indicate mean values from the new and old models, respectively. Note that the observations at Brazzaville and Venezuela are averages of daily maximum values.

reproduced well. Annual average biases are fairly small: $1.6 \mathrm{ppbv}$ at Venezuela, $+0.1 \mathrm{ppbv}$ at Cuiaba, $+5.3 \mathrm{ppbv}$ at $\mathrm{Na}-$ tal and $5.2 \mathrm{ppbv}$ at Brazzaville. The model produces a large fall maximum at Cuiaba, however it is both smaller and one month later than in the observations. This may reflect limitations in our biomass burning emission inventory. Similarly, results at Brazzville show a seasonality which does not agree well with observations as the model underestimates surface ozone during the first half of the year. In contrast, the model tends to overestimate surface ozone during the latter half of the year over many North American sites. The behavior at Rockport, IN shown in Fig. 4 is typical of the results at American sites, with the exceptions of Niwot Ridge, CO, and Custer National Forest, MT, where the model is in much better agreement with the measurements. Over the northeastern portion of the US, four rural observation sites fall within a single model grid box. The comparison (upper right panel of Fig. 4) shows that the model's annual cycle follows the pattern seen in PA much more closely than that seen at the other three locations. This highlights both the difficulty of comparing rural sites with model grid boxes that contain large population centers and the inhomogenaity within a single grid box. The bias towards rural sites in the data may account for much of the overprediction seen in the model simulations of US surface ozone. At other Northern Hemisphere mid-latitude sites, the model performs much better, capturing the magnitude and seasonality at Hohenpeissenberg, Arkona and Mace Head quite well. At high Northern latitudes, the model tends to do a good job reproducing observations except for a positive bias during the wintertime at Reykjavik, Barrow, Strath Valch and Bitmount. In the Southern Hemisphere extratropics, the model matches the mean values quite well at Cape Point, Cape Grim, Syowa and South Pole, however it tends to underestimate the seasonal cycle. An overall 

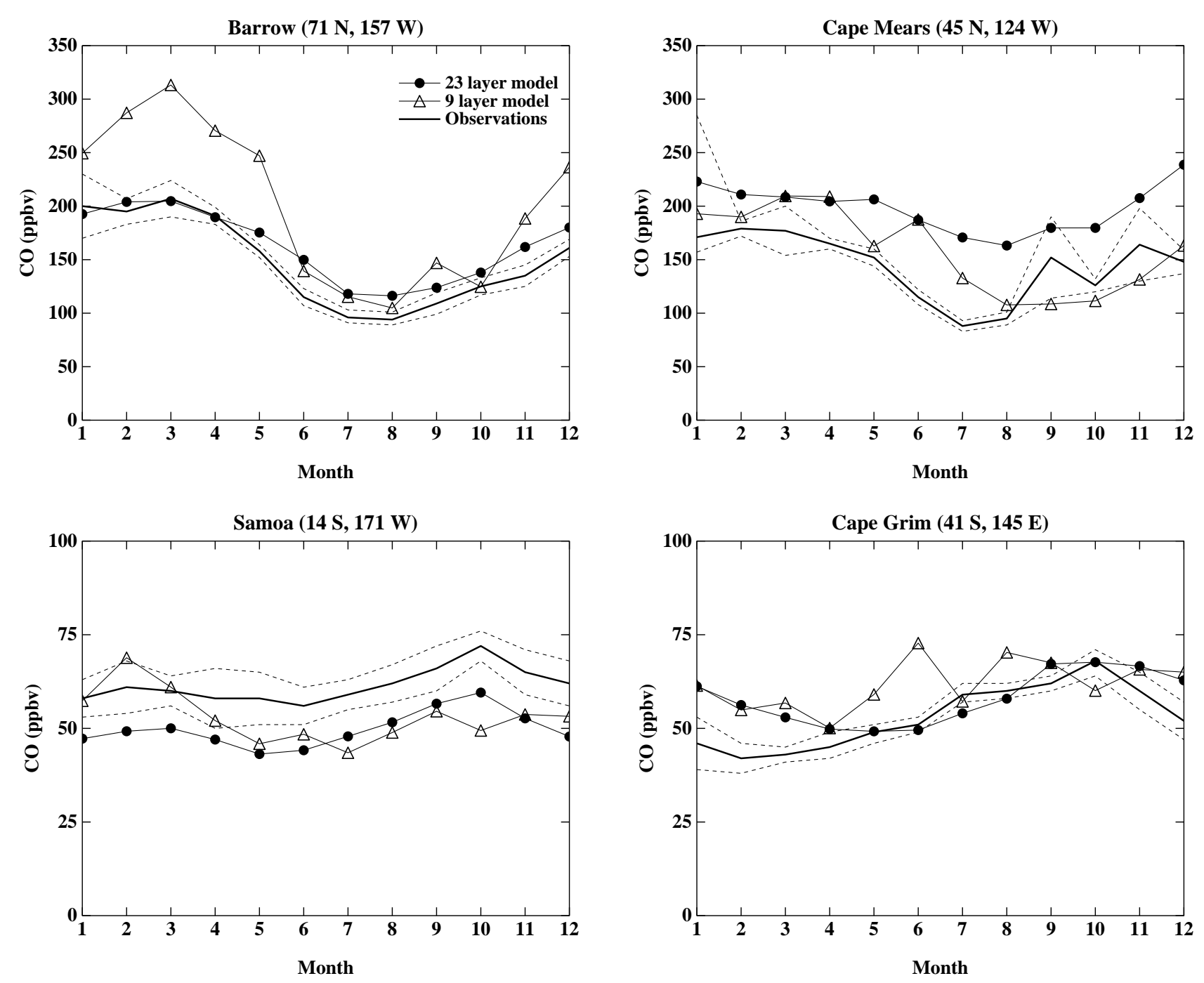

Fig. 5. Comparison of observed and simulated surface carbon monoxide. Solid and dotted lines indicate measured mean values and standard deviations, respectively, while solid circles and open triangles indicate mean values from the new and old models, respectively.

comparison with the 40 sites in the climatology (counting the 4 NE US sites as one) shows the model's mean bias is $+3.8 \mathrm{ppbv}$, with a bias of $+0.9 \mathrm{ppbv}$ in the maximum month and +8.4 in the minimum month. The large number of rural American sites (14, again counting the $4 \mathrm{NE}$ sites only once) means that the large biases there during December contribute strongly to the bias in the minimum value. The new model certainly does a much better job reproducing the observations that the older 9-layer model, which we attribute both to the expanded chemistry scheme and the greater vertical resolution and updated physics in the boundary layer.

The ozone budget in the new model is substantially altered from the previous version. However, we caution that this may not be a very useful indicator of the veracity of ozone simulations. As discussed in Shindell et al. (2001), models report widely differing budget values, yet all profess to simulate observed ozone amounts reasonably well. Furthermore, in testing the gravity-wave drag parameterization in the GCM, we discovered that changes in the stratosphere-troposphere exchange by a factor of two are largely compensated for by adjustment of the chemical and dry deposition terms to yield almost the same ozone fields in most areas. Another example comes from comparing the 9-layer simulation with the simplified chemistry to the 23-layer model with the same chemistry. Going to the higher resolution model reduced the stratosphere-troposphere exchange by $364 \mathrm{Tg} / \mathrm{yr}$. In compensation for the reduced influx, the net tropospheric chemical production increased by $378 \mathrm{Tg} / \mathrm{yr}$, leading to an almost identical ozone burden. Similarly, comparing the simulations of the 23-layer GCM using the previous, simplified chemistry and the present more complex scheme showed that the addition of higher hydrocarbon families and PANs caused an increase in the net chemical production of ozone of $201 \mathrm{Tg} / \mathrm{yr}$. With a similar stratosphere-troposphere exchange in these 
Table 4. $\mathrm{NO}_{\mathrm{x}}$ budget

\begin{tabular}{ll}
\hline Source/sink & Annual mean $\mathrm{Tg} \mathrm{N} \mathrm{yr}^{-1}$ \\
\hline Fossil fuels & 20.9 \\
Soils & 5.8 \\
Biomass burning & 5.8 \\
Lightning & 6.5 \\
Aircraft & 0.6 \\
Stratosphere & $-0.6^{*}$ \\
Chemistry & -36.8 \\
Dry deposition & -2.2 \\
\hline
\end{tabular}

*The stratospheric term varies considerably between runs and with the choice of boundary, being the difference between the much larger upward and downward fluxes, and so is sometimes weakly positive and sometimes weakly negative.

two runs, the dry deposition increased by $191 \mathrm{Tg} / \mathrm{yr}$, largely balancing the chemical changes and leading to an increase of only $18 \mathrm{Tg}$ in the tropospheric ozone burden. Thus the system appears to be highly buffered, and since ozone is approximately in steady-state in the troposphere, changes to a given factor in ozone's budget are largely compensated for by the other terms, resulting in little net effect. Additionally, the net chemistry term is the difference between much larger production and destruction terms, so its changes can be misleading.

In the new model, the tropospheric ozone budget in terms of annual average fluxes $(\mathrm{Tg} / \mathrm{yr})$ is +417 stratospheretroposphere exchange, -1466 dry deposition, and +1049 chemistry. The resulting ozone burden is $349 \mathrm{Tg}$. For comparison, the budget of the previous version was +750 stratosphere-troposphere exchange, -1140 dry deposition, +389 chemistry, and an ozone burden of $262 \mathrm{Tg}$. The values for dry deposition and chemistry found here are quite large, at the high end or outside the range reported for other models. Yet the tropospheric ozone burden is in good agreement with the 236-364 $\mathrm{Tg}$ range reported by other models (Roelofs and Lelieveld, 1995; Levy et al., 1997; Roelofs et al., 1997; Houweling et al., 1998; Wang et al., 1998b; Hauglustaine et al., 1998; Mickley et al., 1999; Stevenson et al., 2000; Lelieveld and Dentener, 2000).

The stratosphere-troposphere exchange was calculated using the flux across the $150 \mathrm{hPa}$ surface for both the 9- and 23layer models. Given the large gradients in the tropopause region, the precise value of the exchange is sensitive to the specific definition chosen. If instead we use the flux across the 250 or $60 \mathrm{hPa}$ surfaces, we find values of 539 or $451 \mathrm{Tg} / \mathrm{yr}$, respectively, in the new model. If we sum the horizontal and vertical fluxes across a surface at $300 \mathrm{hPa}$ poleward of $30^{\circ}$ and at $100 \mathrm{hPa}$ in the tropics, we find a total net flux of $342 \mathrm{Tg} / \mathrm{yr}$. Consistent with this range, the net chemistry term over the varyingly defined troposphere ranges from 1142 to $927 \mathrm{Tg} / \mathrm{yr}$. The stratosphere-troposphere exchange term is the only one to have reasonably good constraints on its global value, which has been given a $450 \mathrm{Tg} / \mathrm{yr}$ best estimate with a $200-870 \mathrm{Tg} / \mathrm{yr}$ range for the cross-tropopause flux from ozone- $\mathrm{NO}_{\mathrm{y}}$ tracer correlations (Murphy and Fahey, 1994), a value of $450-590 \mathrm{Tg} / \mathrm{yr}$ at $100 \mathrm{hPa}$ based on satellite observations (Gettelman et al., 1997) and $390 \mathrm{Tg} / \mathrm{yr}$ at $150 \mathrm{hPa}$ (Mickley et al., 1999) based on fluxes estimated from meteorological data (Appenzeller et al., 1996). Our comparable values are in the range of these estimates, and much better than that seen in our previous model.

If the dry deposition and chemistry were both very much too large, we might expect that although the budget would not be greatly affected since these terms oppose one another, there would be a systematic bias toward underprediction of ozone at low levels and overprediction elsewhere. The comparison with sondes (Fig. 2 and Table 2) does not support such a bias, nor does a comparison with sonde vertical profiles near the surface (not shown). In fact, the improvement in simulated surface ozone in polluted areas is largely attributable to the new planetary boundary layer scheme's enhancement of dry deposition. Based on the observational constraint of the surface measurements and the lowest level sonde data it appears that the faster dry deposition is more reasonable. We therefore believe that the budget is not a very useful constraint, aside from the stratosphere-troposphere exchange term which is better constrained and also provides a useful measure of the influence stratospheric ozone on the troposphere. The key test, however, is that we have demonstrated that the model does a reasonably good job of simulating observed ozone values.

\subsection{Carbon monoxide}

A comparison between observed and simulated annual cycles of surface carbon monoxide at several locations covering a wide range of latitudes is shown in Fig. 5. The model does a good job of matching the measured values, though there are slight positive and negative biases at Cape Mears and Samoa, respectively. Compared with the 9-layer simpler chemistry, this version does a better job of reproducing the observed seasonal cycle (especially at Barrow and Samoa), which now matches the observations fairly well at all locations, though it may be slightly underpredicted at Barrow and Cape Mears. The model has a global mean mass-weighted $\mathrm{OH}$ abundance of $9.7 \times 10^{5}$ molecules $/ \mathrm{cm}^{3}$ for the present day, matching the value of $9.4 \pm 1.3 \times 10^{5}$ molecules $/ \mathrm{cm}^{3}$ derived from measurements of the lifetime of the solvent methyl chloroform (Prinn et al., 2001). The ability of the model to reproduce the mean and seasonal cycle of CO so well implies that the seasonality and amount of hydroxyl is well-simulated. Note that we have chosen to use a much reduced isoprene source in order to improve the carbon monoxide and hydroxyl simulations, despite the lack of observational support for such a source strength, as in recent intercomparisons (IPCC, 2001). If we use the emission source inferred from observations, we 

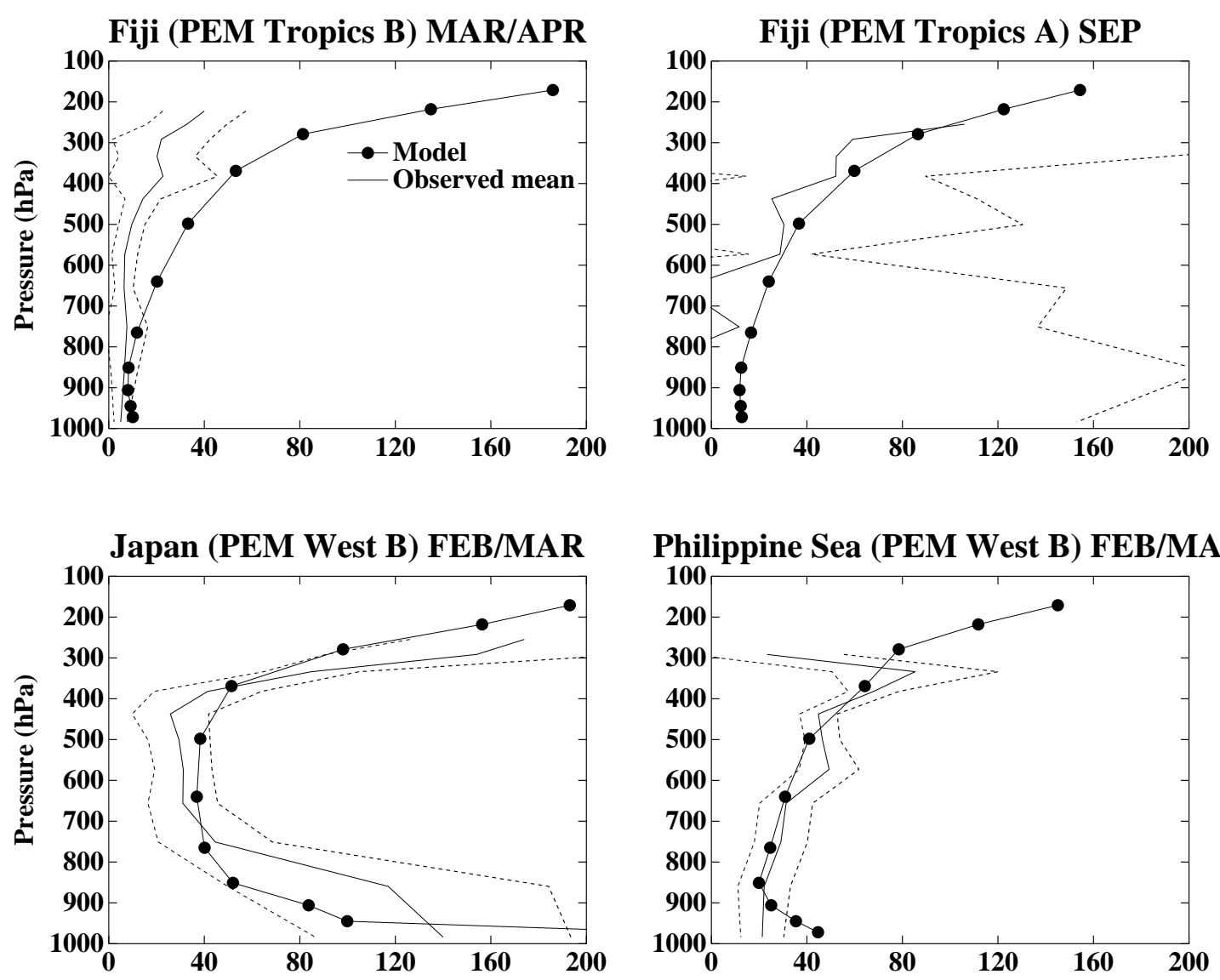

Philippine Sea (PEM West B) FEB/MAR
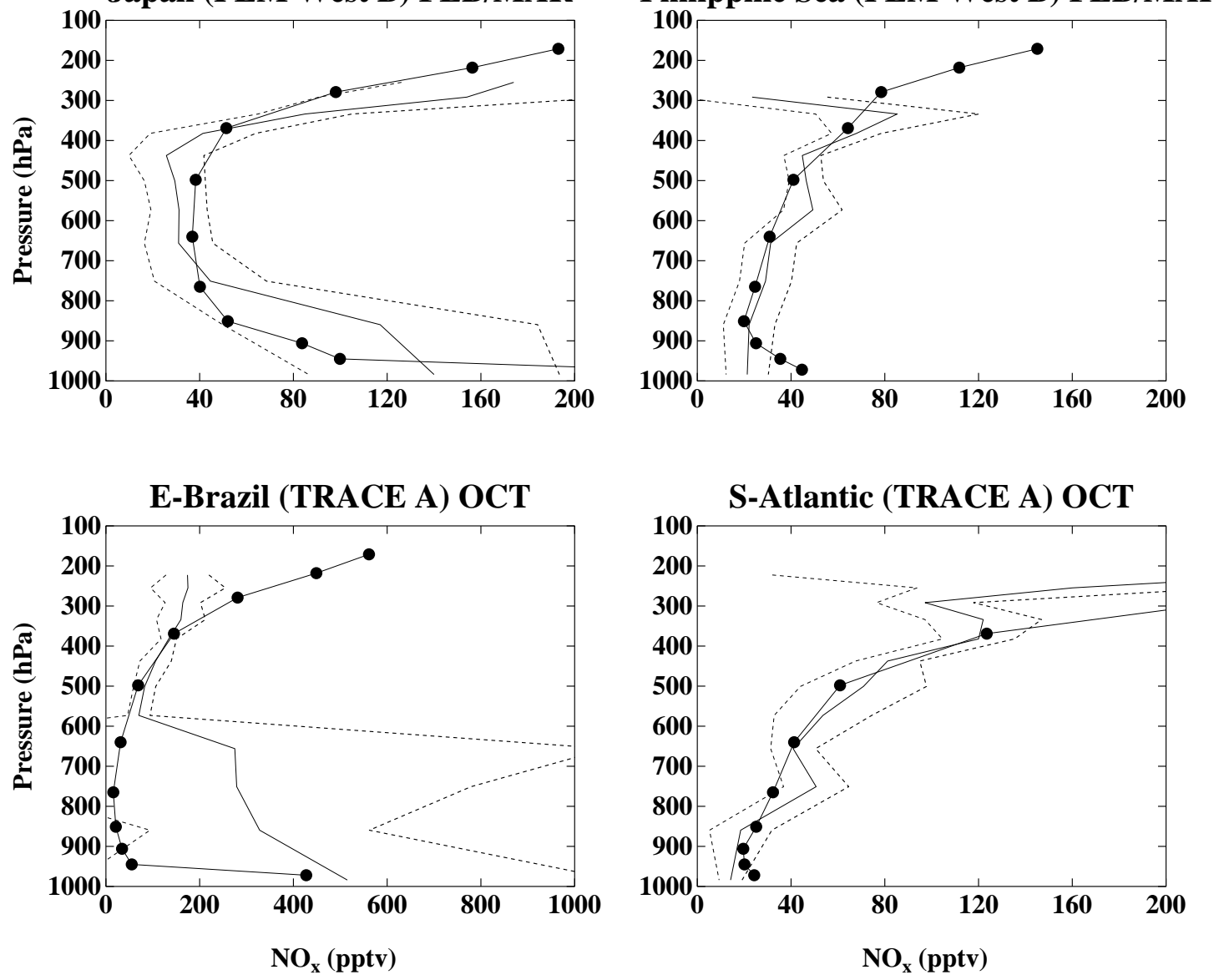

Fig. 6. Observed and simulated profiles of nitrogen oxides and nitric acid for various locations and seasons. Solid and dotted lines indicate measured mean values and standard deviations, respectively. Solid circles show mean values from the new model. Observations are taken from Emmons et al. (2000).

find the typical positive bias in $\mathrm{CO}$ and negative bias in $\mathrm{OH}$ seen in many chemical models (IPCC, 2001). It remains to be determined whether these biases result from deficiencies in current understanding of NMHC chemistry (or our simpli- fied representation of this chemistry), in transport of emitted isoprene out of the canopy, or in some other factor. 

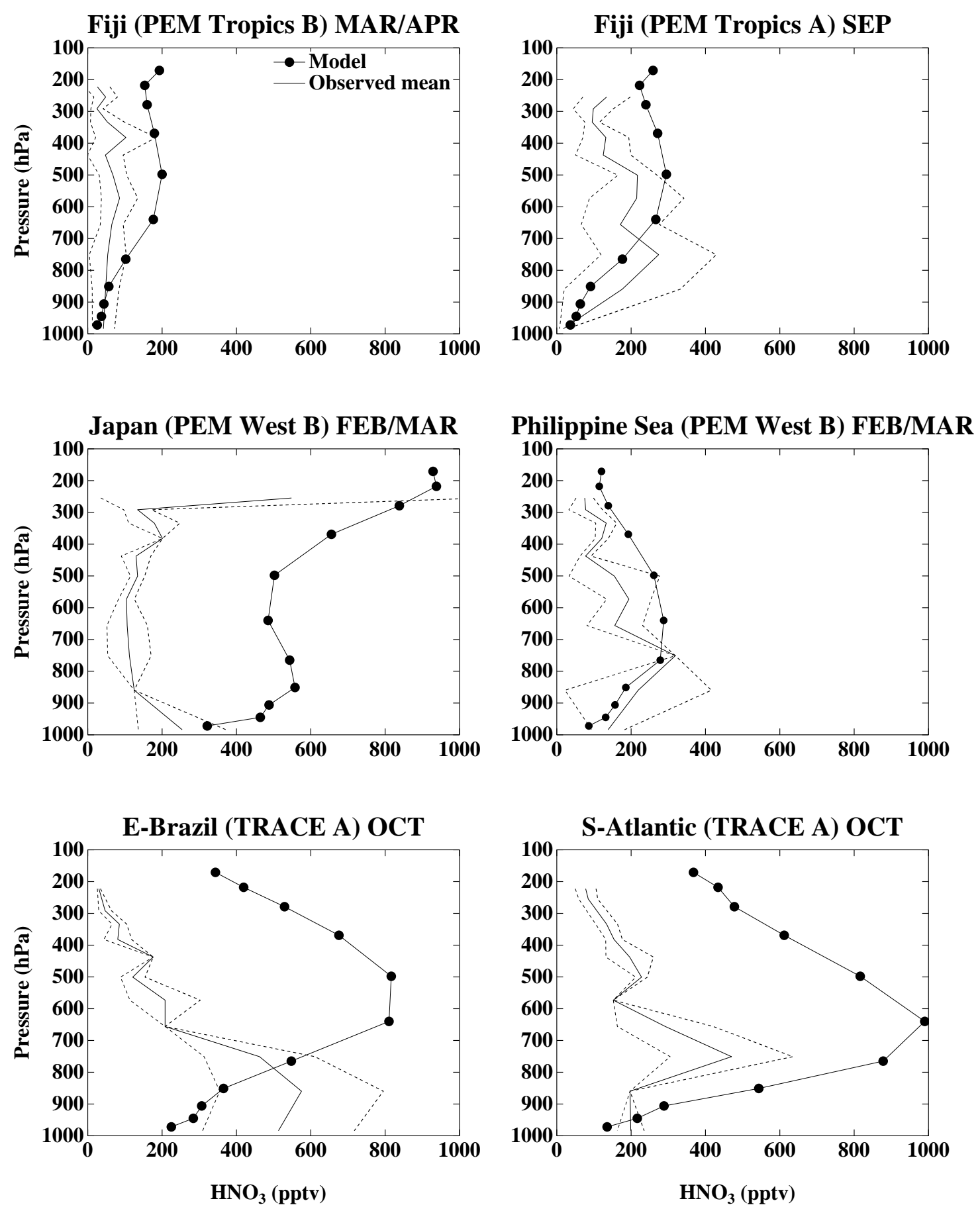

Fig. 6. Continued.

\subsection{Nitrogen species and lightning}

The budget of nitrogen oxides is shown in Table 4. We compare measurements of $\mathrm{NO}_{\mathrm{x}}$ and $\mathrm{HNO}_{3}$ with modeled values in Fig. 6. Observations are not available with long-term coverage from a fixed location as they are with ozone, so we are forced to compare with data obtained during brief field

campaigns as compiled by Emmons et al. (2000). These may not be statistically representative, however. The sample of sites shown in the figure is representative of the behavior of many additional comparisons we performed. The model generally does a good job of reproducing observed profiles of $\mathrm{NO}_{\mathrm{x}}$. This is consistent with the model's ability to accurately simulate ozone. The model is generally capable of 

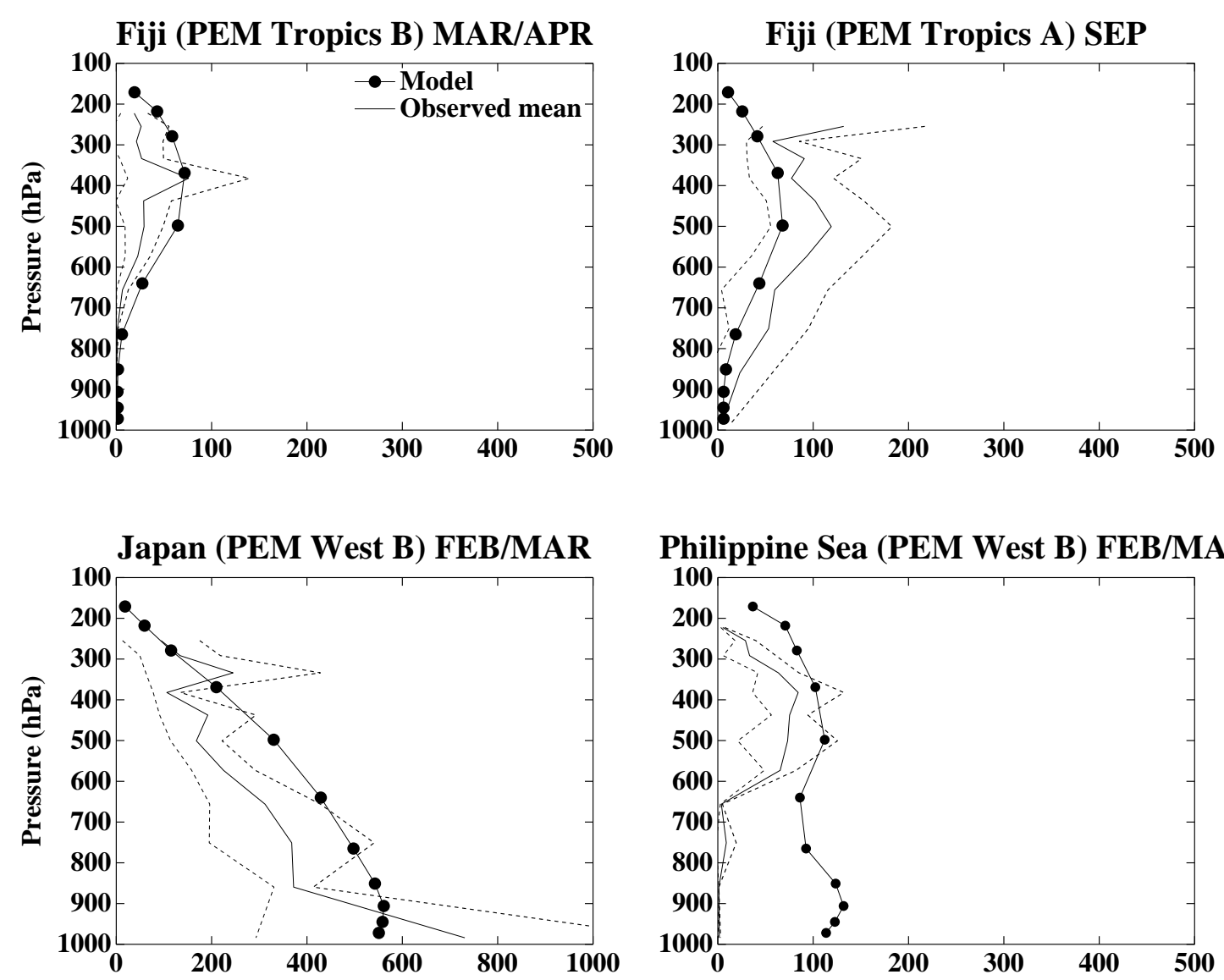

Philippine Sea (PEM West B) FEB/MAR
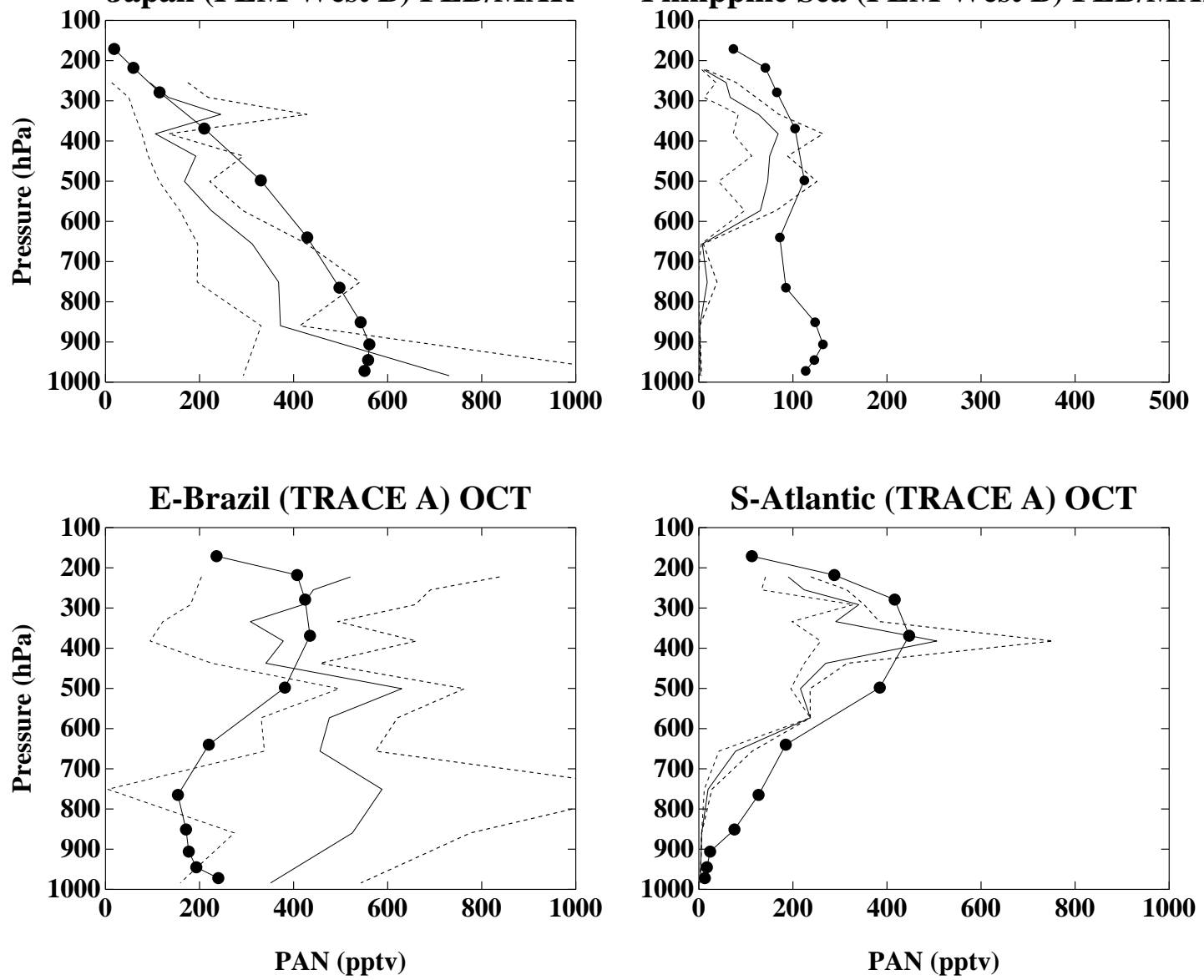

Fig. 7. Observed and simulated profiles of PANs for locations and seasons as in Fig. 6.

generating the very low values in the remote Pacific (Fig. 6). However, in a few regions, such as eastern Brazil (and southern Africa, not shown) the model cannot reproduce the very large values seen in the lower troposphere during the biomass burning period. Out over the South Atlantic the model gives a good match, but the continental values are too low, sug- gesting that at least during the year of the TRACE-A observations, biomass burning emissions of $\mathrm{NO}_{\mathrm{x}}$ may have been larger than those in our inventory. Near highly polluted areas such as Japan, the model does an excellent job of matching the "C-shaped" profile found in observations (Fig. 6). In contrast to $\mathrm{NO}_{\mathrm{x}}$, the model's simulation of $\mathrm{HNO}_{3}$ is often 

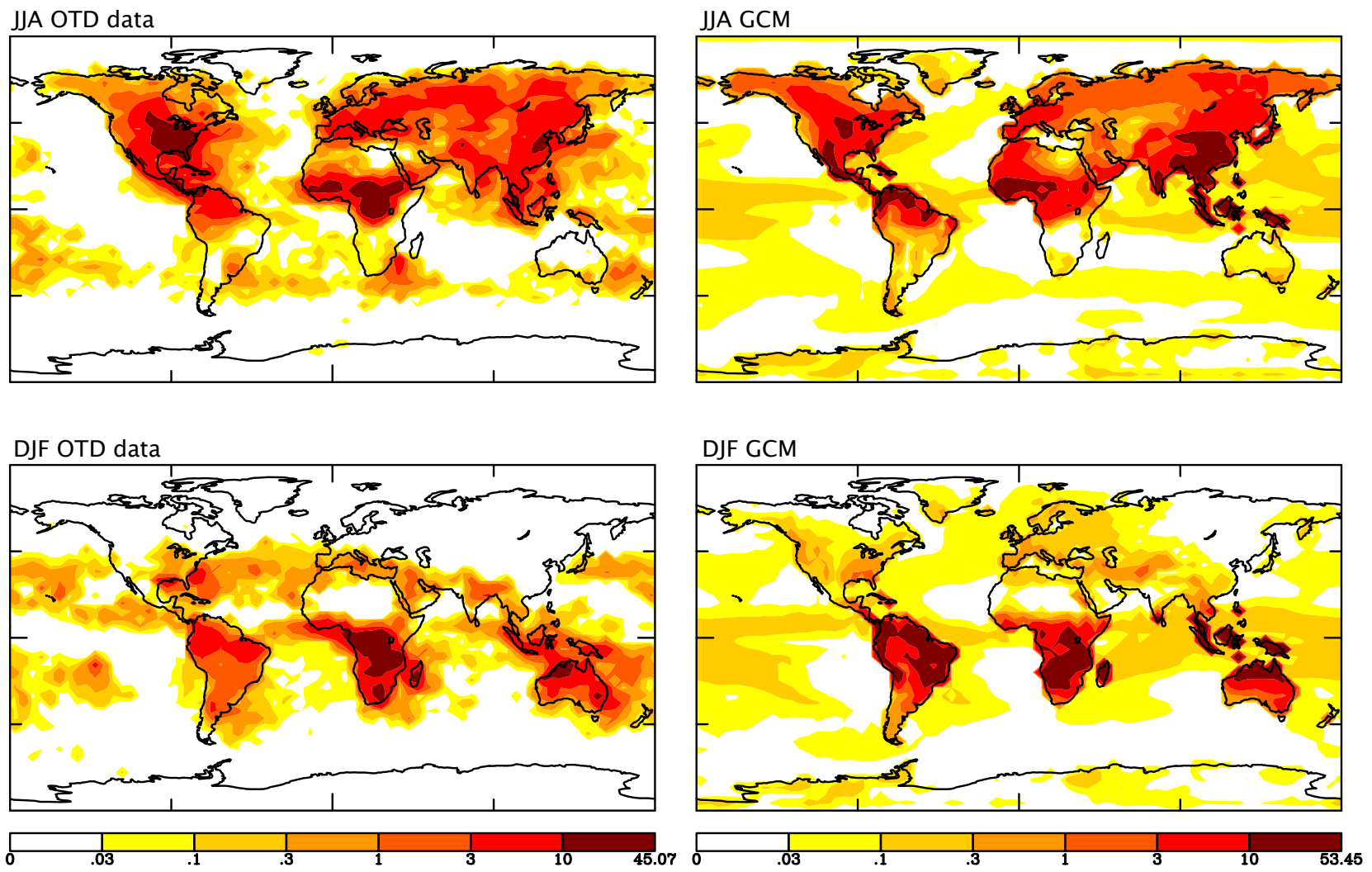

Fig. 8. Observed and simulated distributions of lightning flash rates (flashes $/ \mathrm{km}^{2} / \mathrm{season}$ ). The left column shows observations from the Optical Transient Detector satellite during 1995-1996 (other years look similar), while the right shows model results. The top row is JuneAugust, while the bottom is December-February. Note that there are no satellite observations at high latitudes.

not in accord with observations in polluted regions. While the model mostly matches the observed profiles in the remote Pacific and over the Philippine Sea, it greatly overpredicts nitric acid amounts over eastern Brazil, Japan, and the South Atlantic (Fig. 6), as well as over many other locations near biomass burning regions or industrialized areas (not shown). The overprediction can be a factor of 5 or so, suggesting that the discrepancy is too large to be attributed simply to coarse model resolution or emission uncertainties. An overpredicition of nitric acid is a common problem in tropospheric chemistry models (e.g. Wang et al., 1998b; Mickley et al., 1999), and likely reflects a missing removal mechanism for nitric acid (since the $\mathrm{NO}_{\mathrm{x}}$ values are reasonable). In the future, we intend to fully couple the chemistry in our model to the sulfate aerosol scheme, to consider the inclusion of ammonia chemistry, and to explore heterogeneous reactions on additional surface types such as mineral aerosols and ice which may address this problem. It is also possible that the wet removal of nitric acid is underestimated, perhaps reflecting biases in model precipitation. Additionally, the GCM does not have a separate tracer for dissolved gases, so that all dissolved gases which are not removed in a given time step are returned to the gas phase, which would tend to bias the wet removal towards lower values. This issue will also be addressed in future work.

The model's simulation of PANs is in fairly good agreement with observations in many locations (Fig. 7). PANs are underpredicted over Eastern Brazil during October, consistent with all the nitrogen species, and there is a suggestion of a systematic overestimate in polluted regions. As with nitric acid, we are hopeful that improvement of the model's heterogeneous chemistry will address the latter problem. Additionally, our model uses a family of PANs, while the observations record only PAN itself, creating a systematic difference in the comparison.

The parameterized generation of $\mathrm{NO}_{\mathrm{x}}$ from lightning produces $6.5 \mathrm{Tg} / \mathrm{yr} \mathrm{N}$ in this model. This is significantly larger than the previous model's value of $3.9 \mathrm{Tg} / \mathrm{yr}$, though within the expected range of $2-20 \mathrm{Tg} / \mathrm{yr}$ (WMO, 1999). The difference results primarily from empirically adjusting the parameterization to better match satellite observations (increasing the flashes per convective event coefficients for land and ocean), with smaller contributions from the altered convection scheme in the new model version, and the influence of the model's higher vertical resolution on the lightning $\mathrm{NO}_{\mathrm{x}}$ parameterization. The spatial distribution of flashes is similar 

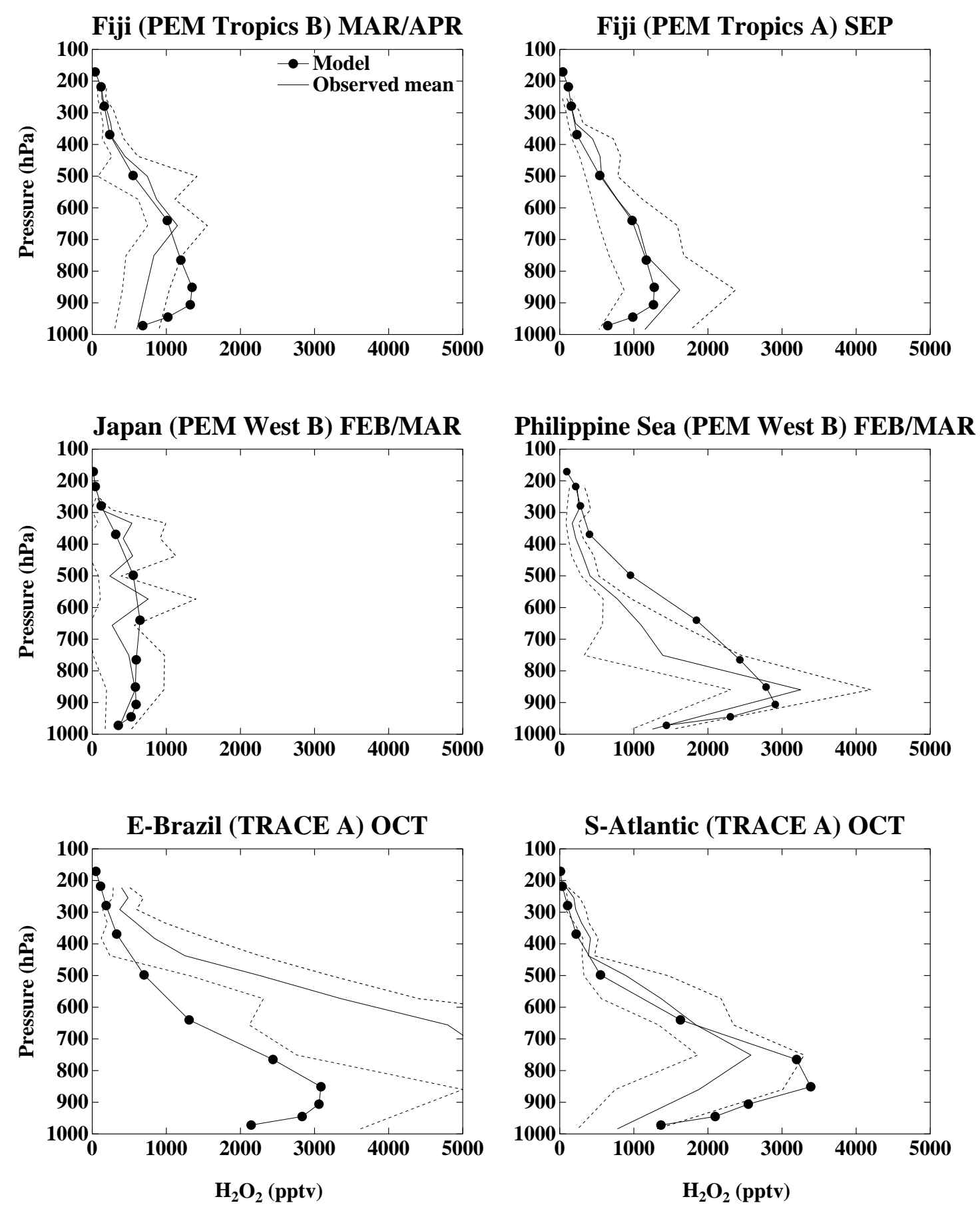

Fig. 9. Observed and simulated profiles of hydrogen peroxide for locations and seasons as in Fig. 6.

to that in the previous model, but is now in better agreement with Optical Transient Detector (OTD) satellite (Boccippio et al., 1998) observations (Fig. 8). The flash frequency averaged over all points is $\sim 4 \%$ greater in the GCM than in the observations, though there are underestimates over the oceans off the eastern edge of continents and over North- ern Hemisphere middle latitudes. The older model produced flash rates $\sim 60-65 \%$ of those observed. This suggests that the new parameterization and convection scheme may give a more realistic overall $\mathrm{NO}_{\mathrm{x}}$ production from lightning. 

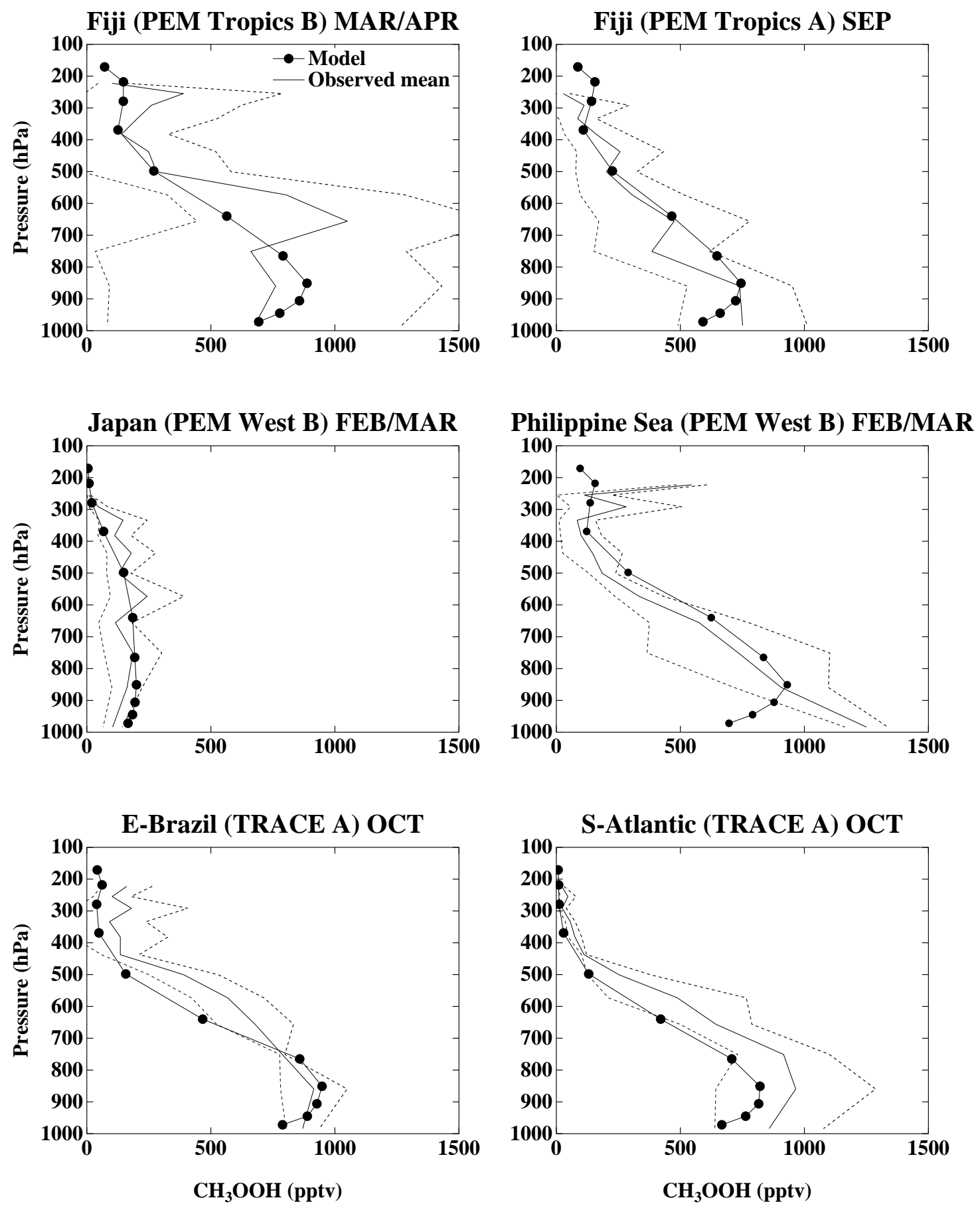

Fig. 10. Observed and simulated profiles of $\mathrm{CH}_{3} \mathrm{OOH}$ for locations and seasons as in Fig. 6.

\subsection{Hydrogen peroxide and methyl hydroperoxide}

The model does a generally good job reproducing observed hydrogen peroxide values in most regions regardless of season (Fig. 9). In contrast to the previous model version, the model is now able to capture the huge enhancement of $\mathrm{H}_{2} \mathrm{O}_{2}$ in the lower troposphere over Brazil in the fall, albeit with a somewhat reduced magnitude (as expected from the $\mathrm{NO}_{\mathrm{x}}$ bias). The model's simulation over southern Africa during this time of year is also improved (not shown). The model exhibits a positive bias in the region of $900 \mathrm{hPa}$ over portions of the Pacific similar to that shown for Fiji during MarchApril, but even larger at Tahiti, Hawaii, and Christmas Island. Given the apparent reasonably good quality of the $\mathrm{OH}$ 

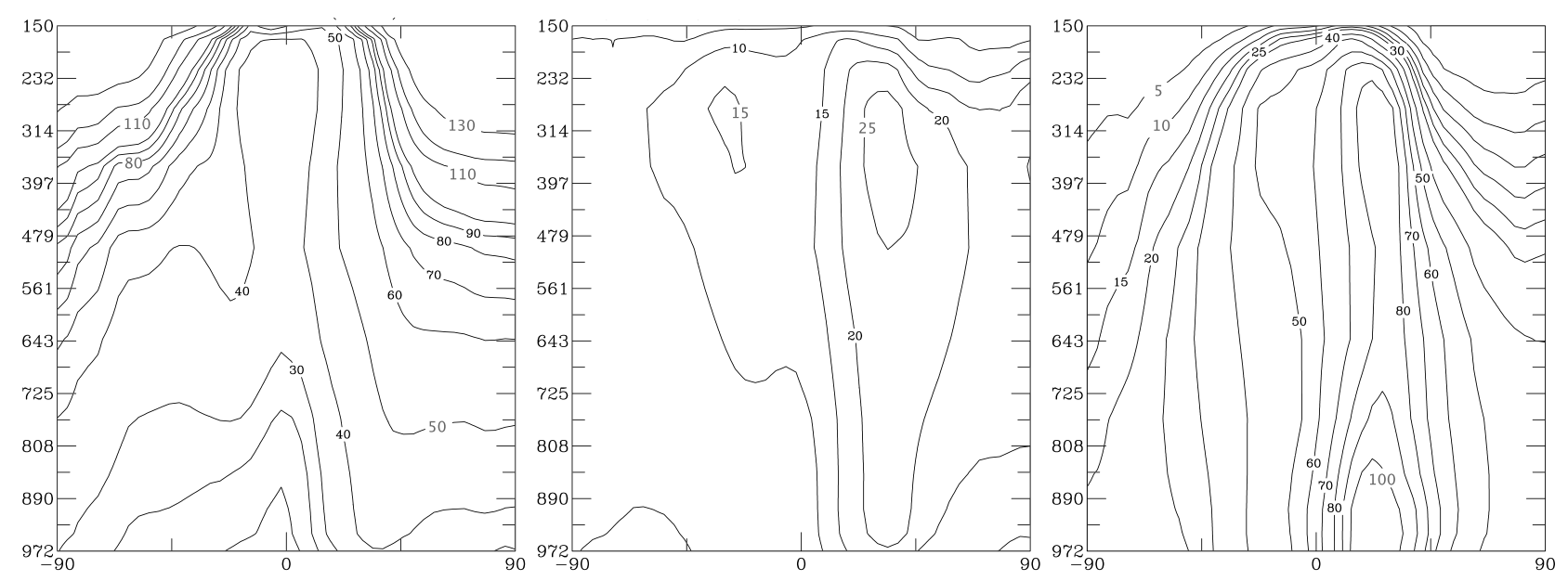

Fig. 11. Zonal mean ozone and ozone changes in the model. (Left) Zonal mean present-day ozone mixing ratios (ppbv). (Middle) The change from preindustrial to the present in mixing ratio (ppbv). (Right) The same change from preindustrial to the present in percent relative to the preindustrial amounts.

simulation, it seems most likely that this is related to an underestimate of wet removal in this region. It is also possible that the model's outflow of polluted air from Asia is too large, leading to too much chemical production of $\mathrm{H}_{2} \mathrm{O}_{2}$. Given the reasonable quality of the simulated nitrogen oxides and nitric acid over the Pacific, however, this seems less likely. The model's lack of both uptake of $\mathrm{HO}_{2}$ on aerosols and in-cloud oxidation of $\mathrm{SO}_{2}$ by $\mathrm{H}_{2} \mathrm{O}_{2}$ may also contribute to the positive bias, which we plan to address in future coupled chemistryaerosol simulations.

The simulation of methyl hydroperoxide $\left(\mathrm{CH}_{3} \mathrm{OOH}\right)$ is also quite good in this model (Fig. 10). The model's values are quite close to those observed for nearly all locations, including both highly polluted regions and the remote $\mathrm{Pa}-$ cific, and for all seasons. Accurate simulation of this important radical intermediate gives us confidence that the model's chemical oxidation of hydrocarbons is being calculated reliably.

\subsection{Methane}

The methane oxidation rate is $431 \mathrm{Tg} / \mathrm{yr}$, consistent with the budget of methane given its large uncertainties. The methane distribution is initialized with observed values since its lifetime is relatively long ( 8.8 years in our simulation). This allows the model to equilibrate rapidly. Given the interhemispheric exchange time of 1.45 years, the methane gradient during most of our simulation is fully equilibrated. The modeled interhemispheric gradient during the last two years of our 7 year simulation is $\sim 150 \mathrm{ppbv}$ (between averages over mid-to-high southern and northern latitudes), in good agreement with comparable 1990 observations (GLOBALVIEW$\left.\mathrm{CH}_{4}, 2001\right)$. This is not too surprising as the global $\mathrm{OH}$ values and the seasonal cycle of $\mathrm{CO}$ agree well with observa- tions, implying that the oxidation is well modeled. We note that the model has more $\mathrm{OH}$ in the Northern Hemisphere than in the Southern, as in most models, but in contrast to the estimates of Prinn et al. (2001) (though those estimates have a very large uncertainty). Were the chemistry to produce an $\mathrm{OH}$ distribution matching those results, the interhemispheric gradient would grow larger. Given current uncertainties in the distribution of emissions, and to a lesser extent in the interhemispheric exchange time, however, this does not necessarily imply that those estimates are unreasonable. The seasonal cycle of methane appears exaggerated at high northern latitudes, however, though it is reasonable in the tropics and in the Southern Hemisphere. Future work will endeavor to improve the seasonality of our methane emissions datasets.

\section{Preindustrial to present-day change}

Many factors related to chemistry and climate have changed since the industrial revolution. A systematic study of the effect of each individual change with our previous model demonstrated that the increased emissions of nitrogen oxides and methane dominated the overall forcing of tropospheric ozone change (Grenfell et al., 2001). To simulate preindustrial conditions in our new model, emissions of anthropogenic ozone precursors were eliminated (fossil fuels, industry and aircraft). Emissions from biomass burning were reduced to one-tenth of their present-day values, a common assumption also used in our earlier experiments. Sulfate surface areas were set to natural background levels as calculated by Koch et al. (1999). Monthly mean sea surface temperatures and sea ice conditions were prescribed according to reconstructed values from the 1870s (Rayner et al., 2003). The cooling relative to the present would be slightly larger 

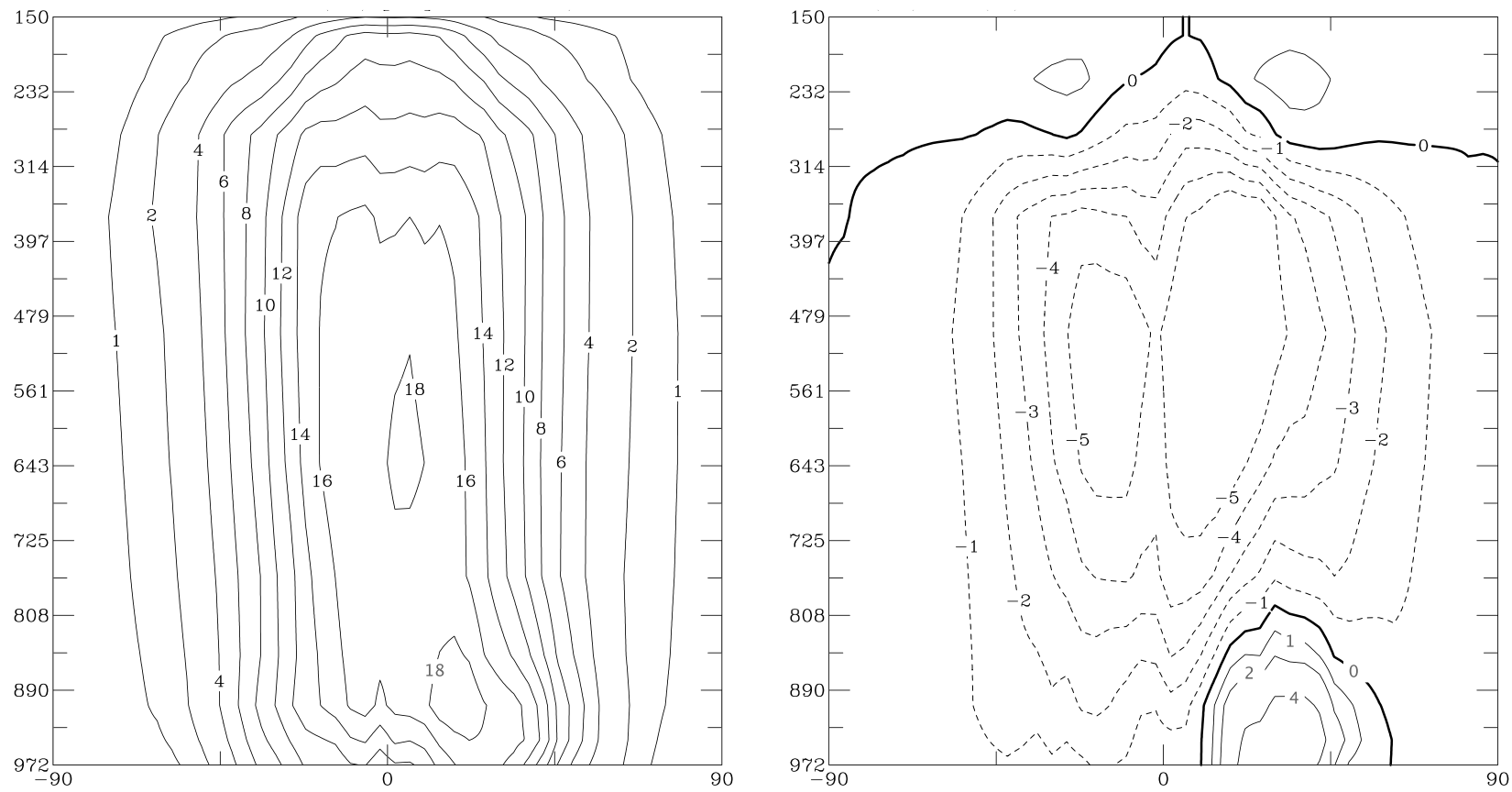

Fig. 12. (Left) Zonal mean hydroxyl in the present-day simulation, and (Right) zonal mean hydroxyl change from the preindustrial to the present. Both panels give values in units of $10^{5}$ molecules $\mathrm{cm}^{-3}$.

for 1850 conditions, but this should have a minimal impact on the results (Grenfell et al., 2001). Concentrations of longlived greenhouse gases were reduced as follows: $\mathrm{CO}_{2}$ from 365 to $280 \mathrm{ppmv}, \mathrm{N}_{2} \mathrm{O}$ from 314 to $275 \mathrm{ppbv}, \mathrm{CH}_{4}$ from 1.745 to 0.700 ppmv, and CFCs to zero. In these simulations, surface types (e.g. vegetation) were kept at presentday values, as was stratospheric ozone. Production of $\mathrm{NO}_{\mathrm{x}}$ by lightning decreased to $6.2 \mathrm{Tg} / \mathrm{yr}$ in the preindustrial simulations, exhibiting a sensitivity to climate change in line with the $+10 \%$ per degree of surface warming for this parameterization (Price and Rind, 1994). Water vapor concentrations were approximately $2-5 \%$ lower throughout the troposphere up to $\sim 300 \mathrm{hPa}$, with marginal increases above that level.

Modeled tropospheric ozone levels have increased markedly since the preindustrial (Fig. 11). Abundances have roughly doubled over much of the Northern Hemisphere from the equator to $45^{\circ} \mathrm{N}$, with increases of more then $100 \%$ at low altitudes. The total tropospheric ozone burden has gone from $255 \mathrm{Tg}$ to $349 \mathrm{Tg}$. This represents an increase of $37 \%$, in accord with the $25-57 \%$ range reported in other models (Levy et al., 1997; Roelofs et al., 1997; Mickley et al., 1999; Lelieveld and Dentener, 2000) and similar to the $45 \%$ increase seen in our earlier simulations (Shindell et al., 2001). The tropospheric ozone budget for the preindustrial simulations is $+449 \mathrm{Tg} / \mathrm{yr}$ from stratosphere-troposphere exchange, $-829 \mathrm{Tg} / \mathrm{yr}$ from dry deposition, and $+380 \mathrm{Tg} / \mathrm{yr}$ from chemistry. The strong dry deposition in this model draws down ozone so much that the net chemical term is positive, in contrast to the previous version. Given that the net term is the difference between two very large production and destruction terms, this change is in fact not as large as it might appear. As with the present day simulations, we caution that the budget values may not provide a very useful measure of the ozone simulation.

Overall, the pattern of ozone increase is fairly similar to that seen in other models and in our earlier simulations. However, the region of greatest increase (in ppbv) has shifted in comparison to our earlier simulations from about $80^{\circ} \mathrm{N}$ between $\sim 600$ and $80 \mathrm{hPa}$ to $40^{\circ} \mathrm{N}$ from $\sim 250$ to $500 \mathrm{hPa}$. In percentage terms, the largest increase in both models takes place at Northern mid-latitudes near the surface. Increases of $80 \%$ now extend up to $250 \mathrm{hPa}$, while in the previous model version these went up to only $\sim 500 \mathrm{hPa}$. The sensitivity above $500 \mathrm{hPa}$ has likely been altered by the addition of non-methane hydrocarbons, which increased ozone production at upper levels, as seen in other models (e.g. Wang et al., 1998c), and the addition of PANs, which provided an efficient pathway for $\mathrm{NO}_{\mathrm{x}}$ emitted at the surface to be transported to the upper troposphere. Enhanced lightning $\mathrm{NO}_{\mathrm{x}}$ relative to the older model may have also contributed to the different response. The stratosphere-troposphere exchange was a greater contributor to tropospheric ozone in the preindustrial simulation than for the present day; $449 \mathrm{Tg} / \mathrm{yr}$ as compared to $417 \mathrm{Tg} / \mathrm{yr}$. Analysis of the ozone fluxes reveals that this was primarily a result of the decreased upward flux of ozone from the troposphere at low latitudes, rather 


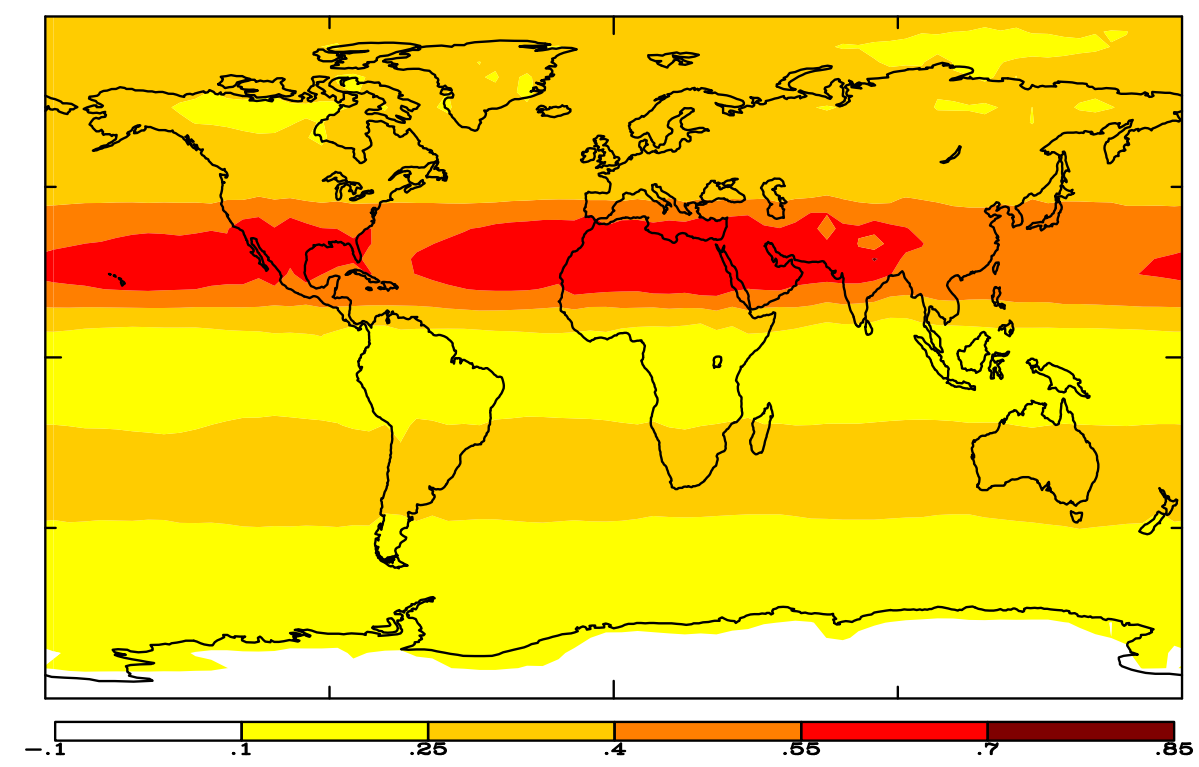

Fig. 13. Global mean annual average radiative forcing at the tropopause from the tropospheric ozone increase between the preindustrial and the present-day $\left(\mathrm{W} / \mathrm{m}^{2}\right)$.

than a sizeable change in the downward flux from the stratosphere. Since the improved vertical resolution allowed a better simulation near the tropopause, and higher hydrocarbons are now included, the ozone changes simulated with the current model should be fairly trustworthy, especially compared with the older model. The large changes in ozone near the tropopause will certainly affect the radiative forcing, which we discuss further below.

The oxidation capacity of the troposphere has also changed since the preindustrial (Fig. 12). Near the surface in the Northern Hemisphere, the large increase in pollution in the present has caused a substantial increase in the abundance of $\mathrm{OH}$, up to $50 \%$ in some locations. Hydroxyl production is increased by direct production via the $\mathrm{O}\left({ }^{1} \mathrm{D}\right)$ reaction with water, which is enhanced both by the global warminginduced increase in water vapor and the ozone pollutioninduced increase in photolytic production of $\mathrm{O}\left({ }^{1} \mathrm{D}\right) . \mathrm{NO}_{\mathrm{x}}$ also directly converts $\mathrm{HO}_{2}$ to $\mathrm{OH}$, so that the increased $\mathrm{NO}_{\mathrm{x}}$ emissions have also led to enhanced $\mathrm{OH}$. At the same time, while increased hydrocarbons generate $\mathrm{HO}_{\mathrm{x}}$ as degradation products, their dominant effect is to reduce the amount of $\mathrm{OH}$ by conversion to $\mathrm{HO}_{2}$. In regions with less abundant $\mathrm{NO}_{\mathrm{x}}$, such as the Southern Hemisphere and the middle and upper troposphere in the Northern Hemisphere, the hydrocarbon increases are more important than $\mathrm{NO}_{\mathrm{x}}$ increases, so that the amount of $\mathrm{OH}$ has decreased in those areas despite the increased ozone and water vapor. In the heavily polluted regions of the Northern Hemisphere, however, the influence of $\mathrm{NO}_{\mathrm{x}}$ outweighs that of hydrocarbons, so that the precursor emission increases add to the overall increase in $\mathrm{OH}$ from enhanced production. The offsetting influences of the regions that show $\mathrm{OH}$ increases with those that show decreases leads to an overall $\mathrm{OH}$ reduction of $13.3 \%$ from the preindustrial to the present. Other models have reported responses ranging from 17\% decreases to 6\% increases (Brasseur et al., 1998; Mickley et al., 1999; Berntsen et al., 1997). The 13.3\% reduction in $\mathrm{OH}$ calculated here yields a comparable increase in the lifetime of methane.

\section{Radiative forcing}

The global mean annual average radiative forcing at the tropopause from the tropospheric ozone increase between the preindustrial and the present-day is $0.30 \mathrm{~W} / \mathrm{m}^{2}$ in these simulations (Fig. 12). The forcing is larger in the Northern Hemisphere, where its average value is $0.38 \mathrm{~W} / \mathrm{m}^{2}$, than in the Southern Hemisphere where its average value is only $0.22 \mathrm{~W} / \mathrm{m}^{2}$. Maximum forcings of $0.7 \mathrm{~W} / \mathrm{m}^{2}$ occur in the Northern subtropics, where the ozone changes also maximized and where sunlight is plentiful. The forcing drops below $0.1 \mathrm{~W} / \mathrm{m}^{2}$ only over Antarctica, where the ozone increases have been smallest and insolation is weakest. The spatial pattern of the forcing in this model looks quite similar to the results of other groups as shown, for example, in the IPCC report (2001). Seasonally, the greatest forcing is during July-August (and is nearly as large during March-May), when the forcing is larger than $0.6 \mathrm{~W} / \mathrm{m}^{2}$ over nearly the entire Northern Hemisphere subtropics and midlatitudes, and surpasses $0.8 \mathrm{~W} / \mathrm{m}^{2}$ over parts of the subtropics (Fig. 14). The radiative forcing was calculated by calling the radiation code twice, once with the climatological ozone and once with the model's calculated distribution, and allowing 

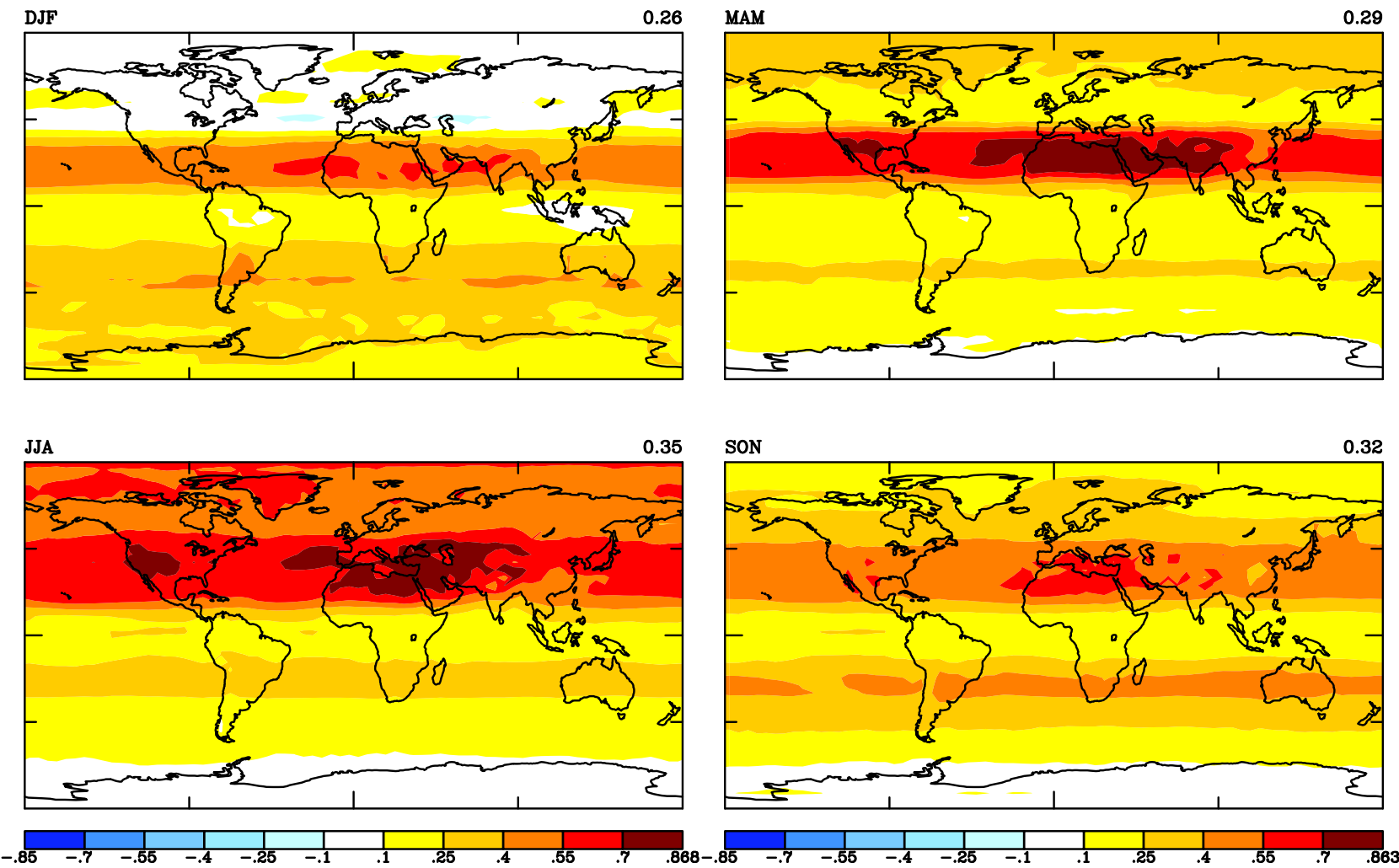

Fig. 14. Seasonally averaged radiative forcing at the tropopause from the tropospheric ozone increase between the preindustrial and the present-day $\left(\mathrm{W} / \mathrm{m}^{2}\right)$. Global mean values are shown in the upper right corner of each plot.

stratospheric temperatures to adjust. Then the change in this difference between the preindustrial and the present-day was calculated. Note that these results are not directly comparable to those presented for our previous model, which were for the top of the atmosphere rather than the tropopause. We believe the latter is a more useful diagnostic. The radiative forcing is primarily driven by absorption of longwave radiation (Fig. 15). Shortwave radiation plays the dominant role only at high latitudes, where the albedo is very high.

The global annual average forcing calculated here, $0.30 \mathrm{~W} / \mathrm{m}^{2}$, is in accord with the range of $0.28-0.55 \mathrm{~W} / \mathrm{m}^{2}$ reported by other three-dimensional global models (Hauglustaine et al., 1994; Roelofs et al., 1997; van Dorland et al., 1997; Berntsen et al., 1997; Stevenson et al., 1998; Haywood et al., 1998; Brasseur et al., 1998; Kiehl et al., 1999; Mickley et al., 1999; Lelieveld and Dentener, 2000). The uncertainty associated with this forcing is quite large, however, as the preindustrial sources are poorly constrained. To explore the range of potential preindustrial ozone levels, we performed an additional preindustrial run setting the soil $\mathrm{NO}_{\mathrm{x}}$ emissions, much of which result from fertilizer application, to one-third their present-day value and increasing the emission of isoprene, paraffins and alkenes from vegetation by half to account for greater forested area in the past, follow- ing Mickley et al. (2001). In the "standard" preindustrial run, all of these emissions were kept unchanged from present-day values. The resulting global mean annual average radiative forcing from the present to the "alternative" preindustrial was $0.33 \mathrm{~W} / \mathrm{m}^{2}$, with a spatial distribution very similar to that seen in the "standard" case (Fig. 13).

A common test of preindustrial simulations is to compare with purported nineteenth century surface observations. We refer to these as "purported" observations due to their lack of quantitative reliability. Nearly all of these measurements were taken with a method known as the Schönbein technique, involving exposure of a chemically treated piece of paper to the air. Modern evaluations of this technique have shown that the results are highly dependent upon a variety of factors, such as the exposure time or the type of paper used, which were not controlled in the early observations (Kley et al., 1988; Pavelin et al., 1999). These results are thus useful primarily in a qualitative sense. The only exceptions are the measurements from Montsouris, which were performed with a quantitative technique (Volz and Kley, 1988) (though even those data were affected by the influence of $\mathrm{SO}_{2}$ and they may only reflect local conditions in the vicinity of Paris (Staehelin et al., 1994)). Though of limited quantitative use, we compare model results from the two preindustrial 

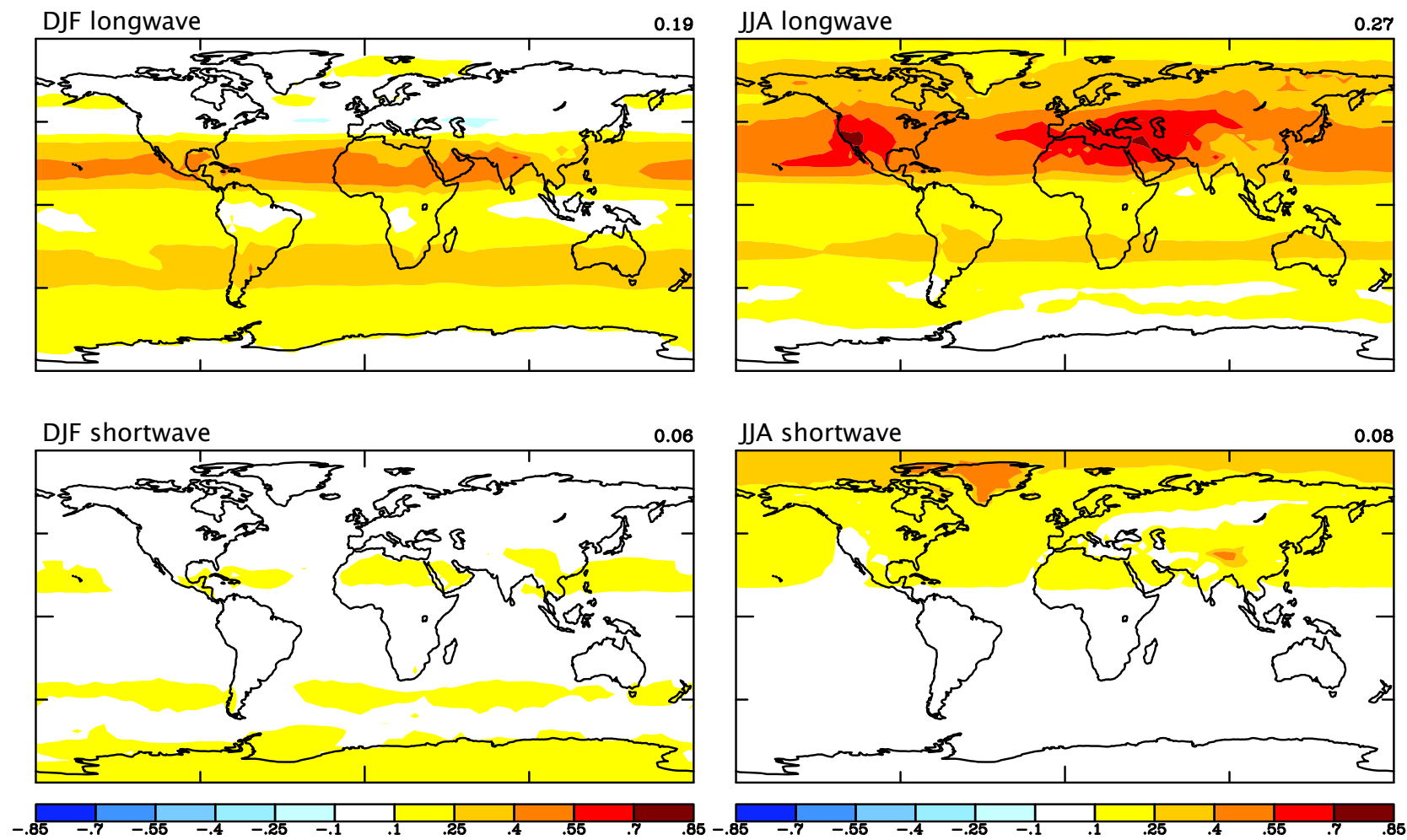

Fig. 15. Summer and winter shortwave and longwave radiative forcing at the tropopause from the tropospheric ozone increase between the preindustrial and the present-day $\left(\mathrm{W} / \mathrm{m}^{2}\right)$. Global mean values are shown in the upper right corner of each plot.

simulations with the nineteenth century purported observations (Fig. 16). The "alternative" simulation appears to do a slightly better job of matching the data points. As with other models (e.g. Mickley et al., 2001), there is a much stronger seasonal cycle at Luanda than in the observations and a mild positive bias remains at Montsouris. In any case, there is certainly no evidence to suggest that the larger ozone changes and radiative forcing associated with the "alternative" preindustrial run are too large.

\section{Discussion and conclusions}

We have developed an improved tropospheric chemistry model which has been coupled to a version of the GISS climate model with enhanced vertical resolution in the boundary layer, near the tropopause, and in the stratosphere. The new chemistry scheme now includes both peroxyacetylnitrates and non-methane hydrocarbons. Through the use of chemical families and a simple explicit chemical solver, the model's computational expense has been kept quite low. Nevertheless, the model does a reasonably good job of reproducing observed annual cycles and vertical profiles of ozone at many locations. The model's main bias is an overestimation of ozone in the middle troposphere at highlatitudes. This has a minimal effect on radiative forcing since insolation is weakest near the poles. The present model calculates a tropopause radiative forcing due to tropospheric ozone increases between the preindustrial and the present of $0.30 \mathrm{~W} / \mathrm{m}^{2}$. Given the increased resolution near the tropopause, a region of paramount importance for radiative forcing, and the improved chemistry, we believe the current results are more trustworthy than those of our earlier simulations.

Uncertainties in the preindustrial to present-day radiative forcing remain large, however, primarily due to the extremely poor constraints on preindustrial emissions of ozone precursors. We performed a test of altered assumptions for preindustrial emissions for comparison with the results of another chemistry model used with a simpler version of the GISS GCM (Mickley et al., 2001). The results of Mickley et al. (1999) showed a radiative forcing of $0.44 \mathrm{~W} / \mathrm{m}^{2}$ in their standard simulations. In our standard preindustrial case, soil $\mathrm{NO}_{\mathrm{x}}$ emissions were unchanged from the present, while in the Mickley et al. (1999) simulations, soil $\mathrm{NO}_{\mathrm{x}}$ emissions from fertilizer were removed. An additional difference between the models is that Mickley et al. (1999) used a larger biomass burning $\mathrm{NO}_{\mathrm{x}}$ source, making the reduction to preindustrial times (based on a $90 \%$ decrease) also larger. However, an additional run of our new model using $7.7 \mathrm{Tg} / \mathrm{yr} \mathrm{N}$ from biomass burning (van Aardenne et al., 2001) compared 

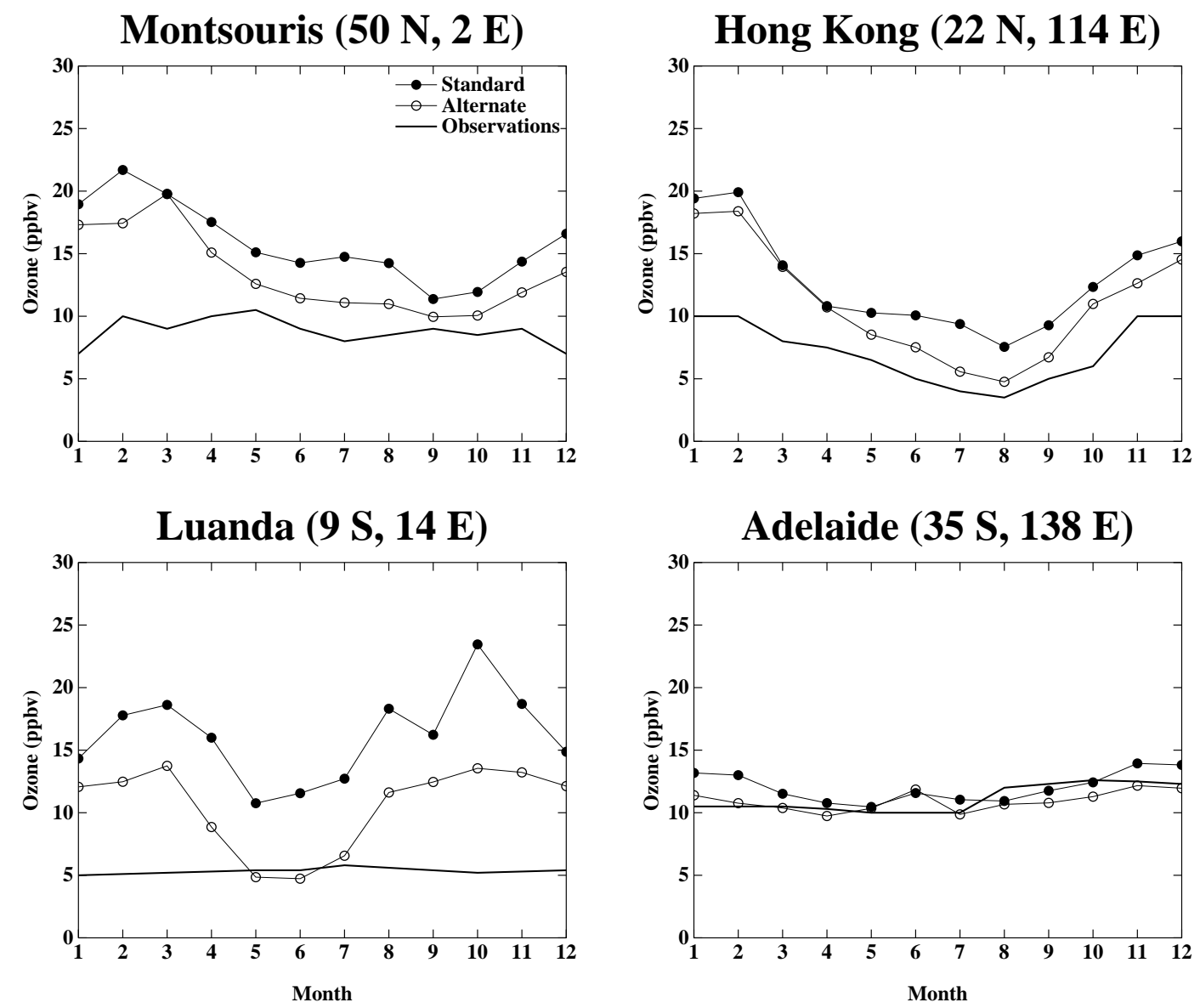

Fig. 16. Comparison between simulated preindustrial surface ozone levels and purported observations at the indicated locations (ppbv). Model results are shown for both standard assumptions for preindustrial sources and for an alternative set of emissions (see text). Observational data have little quantitative reliability.

with the standard preindustrial run gave an identical forcing to our initial present-day simulation (using $5.3 \mathrm{Tg} / \mathrm{yr} \mathrm{N}$ from biomass burning), suggesting that the forcing is not greatly sensitive to these emissions. Overall, the emission differences are consistent with the larger radiative forcing found in Mickley et al's standard preindustrial to presentday case, though differences in the GCM versions used likely also contributed. Using altered assumptions for preindustrial emissions of soil $\mathrm{NO}_{\mathrm{x}}$, hydrocarbons from vegetation, and lightning, Mickley et al. (2001) found a radiative forcing of $0.72-0.80 \mathrm{~W} / \mathrm{m}^{2}$. They concluded that the increased forcing arose primarily from lightning, which they reduced by $43-$ $71 \%$ (1.5-2.5 Tg N/yr). As our lightning change was only $5 \%(0.3 \mathrm{Tg} \mathrm{N} / \mathrm{yr})$, it is not surprising that our alternative simulation of the preindustrial showed less of an increase in the forcing (going from the "standard" $0.30 \mathrm{~W} / \mathrm{m}^{2}$ to the "alternative" $0.33 \mathrm{~W} / \mathrm{m}^{2}$ ). Given current uncertainties in the sensitivity of lightning to climate change, it remains unknown how large the change in that source really has been. Our sensitivity of lightning to climate may be on the low side, how- ever, as a recent study suggests a sensitivity (lightning flash rate increase per degree of surface warming) of $\sim 40 \% / \mathrm{K}$ (Reeve and Toumi, 1999), as opposed to the $\sim 10 \% / \mathrm{K}$ sensitivity in the Price and Rind (1994) parameterization used here. Additionally, our preindustrial simulation was driven by sea-surface temperatures from the 1870s (the earliest in the data set), which neglects a small portion of the warming since the preindustrial, thus giving the lightning less to respond to. Finally, these simulations did not account for any changes in stratospheric ozone, which could have affected both stratosphere-troposphere exchange and the flux of $\mathrm{OH}-$ forming ultraviolet radiation reaching the troposphere.

In addition to using models to estimate the preindustrial to present-day radiative forcing due to tropospheric ozone, another study has examined the earliest available ozone observations dating from the middle part of the twentieth century to evaluate long-term ozone trends (Shindell and Faluvegi, 2002). They concluded that the radiative forcing due to tropospheric ozone increases from the late 1950s to 2000 was $0.38 \pm 0.10 \mathrm{~W} / \mathrm{m}^{2}$. Assuming even a very modest ozone 
buildup prior to 1950 , the forcing since the preindustrial would then have been in the area of $0.5-0.6 \mathrm{~W} / \mathrm{m}^{2}$, on the high side of most global model simulations. Extrapolating based on the rate of increase of $\mathrm{NO}_{\mathrm{x}}$ emissions (van Aardenne et al., 2001), the ozone precursor which is most often rate limiting, the radiative forcing would have been about $0.6 \mathrm{~W} / \mathrm{m}^{2}$ (Shindell and Faluvegi, 2002). Thus the radiative forcing from tropospheric ozone remains poorly constrained from both observations and models, but within the range of plausible values, it may have been one of the most important greenhouse gas forcings of modern climate change.

Acknowledgements. The authors thank NASA's Atmospheric Chemistry Modeling and Analysis Program for support, the Global Hydrology Resource Center at the Global Hydrology and Climate Center for supplying the archived OTD data, J. Logan and L. K. Emmons for kindly providing observational data, Y. Hu for extensive testing and improvements to the GCM's gravity-wave parameterization, and W. Collins and another anonymous referee for their comments.

\section{References}

Appenzeller, C., Holton, J. R., and Rosenlof, K. H.: Seasonal variation of mass transport across the tropopause, J. Geophys. Res., 101, 15 071-15 078, 1996.

Benkovitz, C. M., Scholtz, M. T., Pacyna, J., Tarrason, L., Dignon, J., Voldner, E. C., Spiro, P. A., Logan, J. A., and Graedel, T. E.: Global gridded inventories of anthropogenic emissions of sulfur and nitrogen, J. Geophys. Res., 101, 29 239-29 253, 1996.

Berntsen, T. K., Isaksen, I. S., Myhre, G., Fuglestvedt, J. S., Stordal, R., Larsen, T. A., Freckleton, R. S., and Shine, K. P.: Effects of anthropogenic emissions on tropospheric ozone and its radiative forcing, J. Geophys. Res., 102, 28 101-28 126, 1997.

Boccippio, D. J., Driscoll, K., Koshak, W., Blakeslee, R., Boeck, W., Mach, D., Christian, H. J., and Goodman, S. J.: Cross-sensor validation of the Optical Transient Detector (OTD), J. Atmos. Sol. Terr. Phys., 60, 701-712, 1998.

Brasseur, G. P., Kiehl, J. T., Müller, J. F., Schneider, T., Granier, C., Tie, X., and Hauglustaine, D.: Past and future changes in global tropospheric ozone: Impact on radiative forcing, Geophys. Res. Lett., 25, 3807-3810, 1998.

Cros, B., Delmas, R., Nganga, D., Clairac, B., and Fontan, J.: Seasonal trends of ozone in equatorial Africa: experimental evidence of photochemical formation, J. Geophys. Res., 93, 8355-8366, 1988.

Del Genio, A., Yao, M.-S., Kovari, W., and Lo, K. K.-W.: A prognostic cloud water parameterization for global climate models, J. Clim., 9, 207-304, 1996.

Dentener, F. J. and Crutzen, P. J.: Reaction of $\mathrm{N}_{2} \mathrm{O}_{5}$ on tropospheric aerosols: Impact on the global distributions of $\mathrm{NO}_{\mathrm{x}}, \mathrm{O}_{3}$ and $\mathrm{OH}$, J. Geophys. Res., 98, 7149-7163, 1993.

Derwent, R. G.: Evaluation of a number of chemical mechanisms for their application in models describing the formation of photochemical ozone in Europe, Atmos. Env., 24, 2615-2624, 1990.

Emmons, L. K., Hauglustaine, D. A., Müller, J. F., Carroll, M. A., Brasseur, G. P., Brunner, D., Staehelin, J., Thouret, V., and Marenco, A.: Data composites of airborne observations of tropo- spheric ozone and its precursors, J. Geophys. Res., 105, $20497-$ 20 538, 2000.

Fung, I., John, J., Lerner, J., Matthews, E., Prather, M., Steele, L.P., and Fraser, P.J.: Three-dimensional model synthesis of the global methane cycle, J. Geophys. Res. 96, 13 033-13 065, 1991.

Gery, M. W., Whitten, G. Z., Killus, J. P., and Dodge, M. C.: Development and testing of the CBM-4 for urban and regional modelling, Rep. EPA-600/3-88-012, U. S. Environ. Prot. Agency, Research Triangle Park, NC, 1988.

Gery, M. W., Whitten, G. Z., Killus, J. P., and Dodge, M. C.: A photochemical kinetics mechanism for urban and regional scale computer modeling, J. Geophys. Res., 94, 925-956, 1989.

Gettelman, A., Holton, J. R., and Rosenlof, K. H.: Mass fluxes of $\mathrm{O}_{3}, \mathrm{CH}_{4}, \mathrm{~N}_{2} \mathrm{O}$, and $\mathrm{CF}_{2} \mathrm{Cl}_{2}$ in the lower stratosphere calculated from observational data, J. Geophys. Res., 102, 19 149-19159, 1997.

GLOBALVIEW-CH 4: Cooperative Atmospheric Data Integration Project - Methane. CD-ROM, NOAA CMDL, Boulder, Colorado (Also available on Internet via anonymous FTP to ftp.cmdl.noaa.gov, Path: ccg/ch4/GLOBALVIEW), 2001.

Grenfell, J. L., Shindell, D. T., Koch, D., and Rind, D.: Chemistryclimate interactions in the Goddard Institute for Space Studies general circulation model 2. New insights into modeling the preindustrial atmosphere, J. Geophys. Res., 106, 33 435-33 452, 2001.

Grenfell, J. L., Shindell, D. T., and Grewe, V.: Sensitivity studies of oxidative changes in the troposphere in 2100 using the GISS GCM, Atmos. Chem. Phys., 3, 1267-1283, 2003.

Grewe, V., Brunner, D., Dameris, M., Grenfell, J. L., Hein, R., Shindell, D., and Staehelin, J.: Origin and variability of upper tropospheric nitrogen oxides at northern midlatitudes, Atmos. Env., 35, 3421-3433, 2001.

Grewe, V., Reithmeier, C., and Shindell, D. T.: Dynamical-chemical coupling of the upper troposphere and lower stratosphere region, Chemosphere, 47, 851-861, 2002.

Hansen, J., Sato, M., Ruedy, R., et al.: A Pinatubo climate investigation, in The Effects of Mt. Pinatubo Eruption on the Atmosphere and Climate, NATO ASI Ser. Subser. 1, Global Environment Change, edited by G. Fiocco, D. Fua, and G. Visconti, 233272, Springer-Verlag, New York, 1996.

Hansen, J., Sato, M., and Ruedy, R.: Radiative forcing and climate response, J. Geophys. Res., 102, 6831-6864, 1997.

Hauglustaine, D. A., Granier, C., Brasseur, G. P., and Megie, G.: The importance of atmospheric chemistry in the calculation of radiative forcing on the climate system, J. Geophys. Res., 99, 1173-1186, 1994.

Hauglustaine, D. A., Brasseur, G. P., Walters, S., Rasch, P. J., Müller, J. F., Emmons, L. K., and Carroll, M. A.: MOZART: A global chemical transport model for ozone and related chemical tracers, 2, Model results and evaluation, J. Geophys. Res., 103, 28 291-28 335, 1998.

Hauglustaine, D. A. and Brasseur, G. P.: Evolution of tropospheric ozone under anthropogenic activities and associated radiative forcing of climate, J. Geophys. Res., 106, 32 337-32 360, 2001.

Haywood, J. M., Schwarzkopf, M. D., and Ramaswamy, V.: Estimates of radiative forcing due to modeled increases in tropospheric ozone, J. Geophys. Res., 103, 16999-17 007, 1998.

Hein, R., Crutzen, P. J., and Heimann, M.: An inverse modeling approach to investigate the global atmospheric methane cycle, 
Global Biogeochem. Cycles, 11, 43-76, 1997.

Houweling, S., Dentener, F., and Lelieveld, J.: The impact of nonmethane hydrocarbon compounds on tropospheric photochemistry, J. Geophys. Res., 103, $10673-10$ 696, 1998.

Intergovernmental Panel on Climate Change, Climate Change 2001, Houghton, J. T. et al. (Eds), Cambridge University Press, Cambridge, England, 881 pp, 2001.

Kiehl, J. T., Schneider, T. L., Portmann, R. W., and Solomon, S.: Climate forcing due to tropospheric and stratospheric ozone, J. Geophys. Res., 104, 31 239-31 254, 1999.

Kirchhoff, V. W. J. H.: Surface ozone measurements in Amazonia, J. Geophys. Res., 93, 1469-1476, 1988.

Kirchhoff, V. W. J. H. and Rasmussen, R. A.: Time variations of CO and ozone concentrations in a region subject to biomass burning, J. Geophys. Res., 95, 7521-7532, 1990.

Kley, D., Volz, A., and Mulheims, F.: Ozone measurements in historic perspective, in Tropospheric Ozone, Isaksen, I. S. A. (Ed), D. Reidel Publishing Co., 63-78, 1988.

Koch, D., Jacob, D., Tegen, I., Rind, D., and Chin, M.: Tropospheric sulfur simulation and sulfate direct radiative forcing in the Goddard Institute for Space Studies general circulation model, J. Geophys. Res., 104, 23 799-23 822, 1999.

Lelieveld, J. and Dentener, F. J.: What controls tropospheric ozone?, J. Geophys. Res., 105, 3531-3551, 2000.

Levy, H. II, Kasibhatla, P. S., Moxim, W. J., Klonecki, A. A., Hirsch, A. I., Oltmans, S. J., and Chameides, W. L.: The global impact of human activity on tropospheric ozone, Geophys. Res. Lett., 24, 791-794, 1997.

Logan, J. A.: An analysis of ozonesonde data for the troposphere: Recommendations for testing 3-D models and development of a gridded climatology for tropospheric ozone, J. Geophys. Res., 104, 16 115-16 149, 1999.

Mickley, L. J., Murti, P. P., Jacob, D. J., Logan, J. A., Koch, D. M., and Rind, D.: Radiative forcing from tropospheric ozone calculated with a unified chemistry climate model, J. Geophys. Res., 104, 30 153-30 172, 1999.

Mickley, L. J., Jacob, D. J., and Rind, D.: Uncertainty in preindustrial abundance of tropospheric ozone: Implications for radiative forcing calculations, J. Geophys. Res., 106, 3389-3399, 2001.

Murphy, D. M. and Fahey, D. W.: An estimate of the flux of stratospheric reactive nitrogen and ozone into the troposphere, J. Geophys. Res., 99, 5325-5332, 1994.

Olivier, J. G. J., Bouwman, A. F., Van der Maas, C. W. M., Berdowski, J. J. M., Veldt, C., Bloos, J. P. J., Visschedijk, A. J. H., Zandveld, P. Y. J., and Haverlag, J. L.: Description of EDGAR Version 2.0: A set of global emission inventories of greenhouse gases and ozone-depleting substances for all anthropogenic and most natural sources on a per country basis and on 1x1 grid, RIVM Techn. Report Nr. 771060 002; TNO-MEP report Nr. R96/119, National Institute of Public Health and the Environment, Bilthoven, December 1996.

Oltmans, S. J. and Levy, H.: Surface ozone measurements from a global network, Atmos. Env., 28, 9-24, 1994.

Parrish, D. D., Trainer, M., Holloway, J. S., et al.: Relationships between ozone and carbon monoxide at surface sites in the North Atlantic region, J. Geophys. Res., 103, 13 357-13 376, 1998.

Paulson, S. E. and Seinfeld, J. H.: Development and evaluation of a photooxidation mechanism for isoprene, J. Geophys. Res., 97, 20 703-20715, 1992.
Pavelin, E. G., Johnson, C. E., Rughooputh, S., and Toumi, R.: Evaluation of preindustrial surface ozone measurements made using the Schönbein method, Atmos. Environ., 33, 919-929, 1999.

Pickering, K. E., Wang, Y., Tao, W.-K., Price, C., and Müller, J.F.: Vertical distributions of lightning $\mathrm{NO}_{\mathrm{x}}$ for use in regional and global chemical transport models, J. Geophys. Res., 103, 31203 $31216,1998$.

Prather, M.: Numerical advection by conservation of second-order moments, J. Geophys. Res., 91, 6671-6681, 1986.

Price, C., Penner, J., and Prather, M.: $\mathrm{NO}_{\mathrm{x}}$ from lightning, 1, Global distribution based on lightning physics, J. Geophys. Res., 102, 5929-5941, 1997.

Price, C. and Rind, D.: Possible implications of global climate change on global lightning distributions and frequencies, J. Geophys. Res., 99, 10 823-10 831, 1994.

Prinn, R. G., Huang, J., Weiss, R. F., et al.: Evidence for substantial variations of atmospheric hydroxyl radicals in the past two decades, Science, 292, 1882-1888, 2001.

Rayner, N. A., Parker, D. E., Horton, E. B., Folland, C. K., Alexander, L. V., Rowell, D. P., Kent, E. C., and Kaplan, A.: Global analyses of sea surface temperature, sea ice, and night marine air temperature sine the late nineteenth century, J. Geophys. Res. 108, doi 10.1029/2002JD002670, 2003.

Reeve, N. and Toumi, R.: Lightning activity as an indicator of climate change, Q. J. R. Meteorol. Soc., 125, 893-903, 1999.

Roelofs, G.-J. and Lelieveld, J.: Distribution and budget of $\mathrm{O}_{3}$ in the troposphere calculated with a chemistry general circulation model, J. Geophys. Res., 100, 20 983-20 998, 1995.

Roelofs, G.-J., Lelieveld, J., and Van Dorland, R.: A threedimensional chemistry/general circulation model simulation of anthropogenically derived ozone in the troposphere and its radiative forcing, J. Geophys. Res., 102, 23 389-23 401, 1997.

Sander, S. P., Friedl, R. R., DeMore, W. B., et al.: Chemical kinetics and photochemical data for use in stratospheric modeling, Eval. 13, JPL Publ. 00-003, 2000.

Sanhueza, E., Octavio, K. H., Arrocha, A.: Surface ozone measurements in the Venezuelan tropical savannah, J. Atmos. Chem., 2, 377-385, 1985.

Shindell, D. T., Grenfell, J. L., Rind, D., Price, C., and Grewe, V.: Chemistry climate interactions in the Goddard Institute for Space Studies general circulation model 1. Tropospheric chemistry model description and evaluation, J. Geophys. Res., 106, 8047-8076, 2001.

Shindell, D. T. and Faluvegi, G.: An exploration of ozone changes and their radiative forcing prior to the chlorofluorocarbon era Atmos. Chem. Phys., 2, 363-374, 2002.

Staehelin, J., Thudium, J., Buehler, R., Volz-Thomas, A., and Graber, W.: Trends in surface ozone at Arosa (Switzerland), Atmos. Env., 28, 75-87, 1994.

Stevenson, D. S., Johnson, C. E., Collins, W. J., Derwent, R. G., Shine, K. P., and Edwards, J. M.: Evolution of tropospheric radiative forcing, Geophys. Res. Lett., 25, 3819-3822, 1998.

Stevenson, D. S., Johnson, C. E., Collins, W. J., and Derwent, R. G.: Future estimates of tropospheric ozone radiative forcing and methane turnover - the impact of climate change, Geophys. Res. Lett., 27, 2073-2076, 2000.

Stockwell, W. R., Kirchner, F., Kuhn, M., and Seefeld, S.: A new mechanism for regional atmospheric chemistry modeling, 
J. Geophys. Res., 102, 25 847-25 879, 1997.

Sunwoo, Y. and Carmichael, G.: Characteristics of background surface ozone in Japan, Atmos. Environ., 28, 25-38, 1994.

Tonnesen, S. and Jeffries, H. E.: Inhibition of the odd oxygen production in the carbon bond four and generic reaction set mechanisms, Atmos. Environ., 28, 1339-1349, 1994.

van Aardenne, J. A., Dentener, F. J., Olivier, J. G. J., Klein Goldewijk, C. G. M., and Lelieveld, J.: A $1^{\circ} \times 1^{\circ}$ resolution data set of historical anthropogenic trace gas emissions for the period 1890-1990, Global Biogeochem. Cycles, 15, 909-928, 2001.

van Dorland, R., Dentener, F. J., and Lelieveld, J.: Radiative forcing due to tropospheric ozone and sulfate aerosol, J. Geophys. Res., 102, 28 079-28 100, 1997.

Volz, A. and Kley, D.: Evaluation of the Montsouris series of ozone measurements made in the nineteenth century, Nature, 332, 240 242, 1988.

Walter, B. P., Heimann, M., and Matthews, E.: Modeling modern methane emissions from natural wetlands 1 . Model description and results, J. Geophys. Res., 106, 34 189-34 206, 2001.
Wang, Y., Jacob, D., and Logan, J.: Global simulation of tropospheric $\mathrm{O}_{3}-\mathrm{NO}_{\mathrm{x}}$ hydrocarbon chemistry, 1, Model formulation, J. Geophys. Res., 103, 10713-10 725, 1998a.

Wang, Y., Jacob, D., and Logan, J.: Global simulation of tropospheric $\mathrm{O}_{3}-\mathrm{NO}_{\mathrm{x}}$ hydrocarbon chemistry, 2, Model evaluation and global ozone budget, J. Geophys. Res., 103, 10727-10 755, 1998 b.

Wang, Y., Jacob, D., and Logan, J.: Global simulation of tropospheric $\mathrm{O}_{3}-\mathrm{NO}_{\mathrm{x}}$ hydrocarbon chemistry, 3, Origin of tropospheric ozone and effects of nonmethane hydrocarbons, J. Geophys. Res., 103, 10757-10767, 1998c.

Wild, O., Zhu, X., and Prather, M. J.: Fast-J: Accurate simulation of in- and below-cloud photolysis in tropospheric chemical models, J. Atmos. Chem., 37, 245-282, 2000.

World Meteorological Organization, Scientific assessment of ozone depletion: 1994, Rep. 37, Geneva, 1995.

World Meteorological Organization, Scientific assessment of ozone depletion: 1998, Rep. 44, Geneva, 1999. 